\title{
Drugs-related cardiomyopathy: A systematic review and pooled analysis of pathophysiology, diagnosis and clinical management
}

\author{
Aref Albakri* \\ Department of Internal Medicine, St-Marien hospital Bonn Venusberg, Bonn, Germany
}

\begin{abstract}
Drug-induced cardiomyopathy (CM) is a potentially reversible form of acquired $\mathrm{CM}$ and a common consequence of exposure to numerous medically prescribed drugs. It is particularly a common serious adverse side effect of anticancer and antiretroviral therapies. The two drugs may have significantly improved longevity in cancer and HIV-infected patients respectively but their cardiotoxic effects threaten to undermine their therapeutic efficacy and reduce survival in affected patients. Hospitalization due to drug-induced CM also places a considerable burden on the healthcare system in terms of reduced drug efficacy and patient management. Early detection is clinically important for improve efficacy in the management of drug-induced $\mathrm{CM}$ as well as the prevention of the progression into heart failure. Thus, prescribers should be fully aware of drugs with the potential to cause CM and the clinical value of monitoring the cardiotoxic effects of these drugs. Thus, the present paper provides a systematic review of literature and meta-analysis of diagnosis and management methods. The aim is to broaden the understanding of the major causative drugs, pathophysiology, diagnosis and management of drug-induced CM.
\end{abstract}

\section{Introduction}

Cardiomyopathies (CM) are a heterogeneous group of myocardial (heart muscle) diseases and an important cause of heart failure (HF) and cardiovascular death [1,2]. Its frequent aetiology is genetic although acquired aetiologies can also cause the disease [3]. Unfortunately, a significant portion of acquired CM may result from the use (and misuse) of drugs. Indeed, the heart is a recognized target of injury for many drugs, both medically prescribed and recreational drugs $[3,4]$. Hospitalization due to drug-induced CM places a significant burden on the healthcare system in terms of reduced drug efficacy and patient management. In particular, cases of CM related to prescription drugs predominantly chemotherapy and highly active antiretroviral therapy (HAART) are on the rise. Although these drugs have improved longevity in cancer survivors and HIV-positive patients, long-term complications on the patient's health due to reduced therapeutic effectiveness is on the increase. Thus, it is important that prescribers are fully aware of the serious adverse cardiac effect of cytotoxic drugs and the value of monitoring of at risk patients. It is the aim of the present review, to aggregate published evidence on drug-induced CM with a particular focus on causative drugs, pathophysiology, diagnosis and clinical management.

\section{Clinical definition}

The American Heart Association (AHA) scientific statement on contemporary definitions and classification of the cardiomyopathies defines CM as a heterogeneous group of diseases of the myocardium associated with mechanical and/or electrical dysfunction that usually (but not invariably) exhibit inappropriate ventricular hypertrophy or dilatation and are due to a variety of causes that are frequently genetic. The disease either is confined to the heart or is a part of a generalized systemic disorder, often leading to cardiovascular death or progressive
HF-related disability [1]. Thus, drug-induced CM may be defined as a form of non-genetic $\mathrm{CM}$ resulting from the exposure to prescription or recreational drugs associated with the failure of myocardial performance, which may be mechanical (systolic or diastolic dysfunction) or perturbations to the cardiac conduction system and prone to life-threatening arrhythmias. In the present paper, the focus is on drug-induced CM primarily due to medically prescribed drugs.

\section{Drugs inducing cardiomyopathy}

Chronic exposure to various drugs with cardiotoxic effect can potentially result in drug-induced CM even when used appropriately. However, drug-induced $\mathrm{CM}$ is particularly prominent in cancer patients on chemotherapy (anti-cancer) drugs mostly anthracyclines, cyclophosphamide trastuzumab and tyrosine kinase inhibitors [5]. Non-cancer drugs with the potential to cause drug-induced CM include antiretroviral drugs (zidovudine, didanosine and zalcitabine), and antipsychotic drugs (phenothiazines and clozapine) [6].

\section{Anti-cancer drugs}

Chemotherapeutic agents: Chemotherapy drugs used in cancer treatment are a prominent cause of cardiotoxicity and drug-induced CM. As survival of cancer patients continues to improve, drug cardiotoxicities feature more prominently in the long-term patient outcomes. Most common chemotherapeutic agents implicated as

${ }^{\star}$ Correspondence to: Aref Albakri, department of Internal Medicine, St-Marien hospital Bonn Venusberg, Bonn, Germany, E-mail: arefalbakri@yahoo.com

Key words: anticancer drugs, antiretroviral drugs, antipsychotic drugs, druginduced cardiomyopathy, chemotherapy, cytotoxic drugs

Received: May 20, 2019; Accepted: June 12, 2019; Published: June 19, 2019 
a major cause of $\mathrm{CM}$ are anthracyclines, monoclonal antibodies (trastuzumab), alkylating agents (cyclophosphamide), and tyrosine kinase inhibitors (sunitinib and imatinib). Table 1 presents a summary of the most common anti-cancer drugs causing $\mathrm{CM}$ alongside their cardiotoxicity characteristics, risk factors and methods of monitoring $[6]$.

Anthracyclines: Myocardial damage from chronic exposure to cytotoxic agents used in the treatment of a wide range of hematologic and solid malignancies have been described for more than five decades [6]. By far, the most commonly recognized type of chemotherapy drugs with direct cardiotoxic effect are anthracyclines-based [3]. These drugs still form an integral part of the current anti-cancer treatment although their cardiotoxicity has been well documented. At present, various formulations of anthracycline-based drugs including doxorubicin, daunorubicin, epirubicin, idarubicin, and mitoxantrone are in regular use in oncologic practice $[3,5,6]$. Risk factors for the development of anthracycline-induced CM are multifactorial including dosage, older age ( $>70$ years), diabetes, gender, hypertension, liver disease, poor nutrition, mediastinal radiotherapy, prior cardiac disease or concomitant administration of other anti-neoplastic agents such as cyclophosphamides, actinomycin D, bleomycin, cisplatin and methotrexate [7-10]. The risk of drug-induced CM increases significantly at cumulative doses of $550 \mathrm{mg} / \mathrm{m}^{2}$ although CM may still occur at lower doses [11]. In modern trials of adjuvant anthracycline therapy, reported incidence of $\mathrm{CM}$ is $\leq 2 \%$ but recent studies have reported up to $10 \%$ and $50 \%$ cases of subclinical decline in LVEF greater than $10 \%$ after anthracycline treatment [12].

Anthracycline-induced $\mathrm{CM}$ usually manifests as ventricular dysfunction (based on a combined index of signs, symptoms and declining LVEF) and clinical HF [3]. Early detection and treatment of LV dysfunction after anthracycline treatment can significantly reduce the incidence of clinical HF, which generally occurs within a month to a year but there are cases of HF manifesting up to six to twenty years after anthracycline therapy $[7,8]$. As the efficacy of chemotherapy continues to improve, the population of long-term survivors of childhood cancer is growing, and with it increased detection of late onset CM in adulthood after anthracycline treatment in childhood [13]. The prognostic factors for anthracycline-induced CM include time course of treatment and the presence of pre-existing additional risk factors for myocardial injury such as radiation, concomitant coronary artery disease and pre-existing cardiac dysfunction. The occurrence of HF suggests poor prognosis comparable to that of idiopathic or ischemic CM [3]. Prior radiotherapy to the heart or mediastinum has also been described to increase the risk of developing anthracycline-induced CM. Other important factors that may influence LVEF in patients receiving anthracycline-based therapies include fluid overload, sepsis, ischemic heart disease, and concomitant dose of other chemotherapy drugs $[3,5,6]$.

Trastuzumab: Trastuzumab is a humanized monoclonal antibody that directly inhibits the human epidermal growth factor receptor 2 (HER2) protein pathway [14]. HER2 normally helps in the growth, proliferation, repair and control of abnormal cells [15]. HER2 occurs in up to $30 \%$ of breast cancer patients and are associated with an elevated risk of brain metastases, reduced response to hormonal therapy and increased risk of recurrence and death [15-17]. Trastuzumab binds to the extracellular domain of HER2 and inhibits the activation of intracellular tyrosine kinase, and is used as a first-line therapy for breast cancer that has overexpression of HER2, where it has been shown to be effective in $25 \%$ to $30 \%$ of the cases [18-19]. Treatment with trastuzumab for one year after standard chemotherapy has been shown to improve outcomes in patients with HER2-positive breast cancer [20].

Trastuzumab-induced cardiotoxicity usually manifests as asymptomatic decrease in LVEF, which may lead to complications such as systemic HF [14]. The cardiotoxic effect develops early usually within weeks of initial treatment, and in contrast to anthracyclines, trastuzumab-induced cardiotoxicity is independent of dosing regimens. The cardiotoxicity is also transient and reversible, and does not show typical anthracycline-induced cardiomyocyte necrosis or cardiomyocyte damage on cardiac biopsy [21]. Concurrent or prior use of other cardiotoxic chemotherapy drugs (mostly anthracyclines but also cyclophosphamide or paclitaxel) has been reported as the major risk factor for development of trastuzumab-induced CM in several studies [22-26]. In contrast, risk factors such as radiation, diabetes, valvular heart disease or coronary artery disease do not appear to increase the risk of trastuzumab-induced CM [25,27-29]. However, the clinical use of trastuzumab is relatively new and full understanding of long-term cardiotoxicities is still evolving.

Other monoclonal antibodies with the potential to cause CM, although infrequently, include rituximab and interleukins. Rituximab is a monoclonal antibody that acts on CD20 antigen found on the surface of malignant and normal B-lymphocytes [30,31]. It is

Table 1. Characteristics of cardiotoxicity of CM-associated chemotherapeutic agents

\begin{tabular}{|c|c|c|c|}
\hline Drug & Cardiotoxicity & Risk Factors & Monitoring \\
\hline $\begin{array}{l}\text { Anthracycline (doxorubicin, daunorubicin, } \\
\text { epirubicin, idarubicin, mitoxantrone) }\end{array}$ & $\begin{array}{l}\text { HF, LV dysfunction, non-specific } \\
\text { ECG changes and arrhythmias usually } \\
\text { not clinically significant. Rare fatal } \\
\text { myopericarditis }\end{array}$ & $\begin{array}{l}\text { Increased HF risk at doses }>550 \mathrm{mg} / \\
\mathrm{m}^{2} \text {, older age ( }>65 \text { years), prior chest } \\
\text { radiotherapy, prior history of cardiac disease. } \\
\text { Risk reduced with continues (instead of } \\
\text { rapid) infusion or concurrent administration } \\
\text { of dexrazoxane. }\end{array}$ & $\begin{array}{l}\text { Serial assessment of LV function beyond } \\
\text { cumulative doses } \sim 360 \mathrm{mg} / \mathrm{m}^{2} \text {. Routine } \\
\text { echocardiogram at } 3-6 \text { months, } 12 \text { months } \\
\text { and 2-5 years after therapy completion or if } \\
\text { LV dysfunction is clinically suspected. }\end{array}$ \\
\hline Monoclonal antibodies (trastuzumab) & HF, LV dysfunction & $\begin{array}{l}\text { Risk of HF, LV dysfunction increased when } \\
\text { given in combination with anthracyclines, } \\
\text { cyclophosphamide or paclitaxel. }\end{array}$ & $\begin{array}{l}\text { Serial assessment of LV function during } \\
\text { treatment. At end of therapy, continued } \\
\text { clinical follow-up with echocardiogram } \\
\text { but optimal duration and frequency not yet } \\
\text { established. }\end{array}$ \\
\hline $\begin{array}{l}\text { Tyrosine kinase inhibitors (sunitinib, } \\
\text { imatinib) }\end{array}$ & HF, LV dysfunction & $\begin{array}{l}\text { HF generally improves after cessation of } \\
\text { treatment }\end{array}$ & $\begin{array}{l}\text { Re-assessment of LV function during } \\
\text { treatment as clinically indicated or if LV } \\
\text { dysfunction is clinically suspected }\end{array}$ \\
\hline Alkylating agents (cyclophosphamide) & Myocarditis, HF & $\begin{array}{l}\text { Acute toxicity occurs at } 1 \text { to } 10 \text { days } \\
\text { after treatment. Rare occurrence of } \\
\text { haemorrhagic myocarditis. HF risk increases } \\
\text { with cumulative dose or after prior chest } \\
\text { radiotherapy or anthracyclines. }\end{array}$ & $\begin{array}{l}\text { Clinical monitoring for signs of toxicity } \\
\text { during treatment for HF or myocarditis } \\
\text { and long-term for HF with assessment of } \\
\text { LF function if LV dysfunction is clinically } \\
\text { suspected }\end{array}$ \\
\hline
\end{tabular}


frequently used for the treatment of non-Hodgkin's lymphoma, chronic lymphocytic leukaemia (CLL), rheumatoid arthritis (RA), and antineutrophilic cytoplasmic antibody (ANCA)-associated vasculitis [32,33]. Rituximab may cause hypotension, angioedema, arrhythmias and acute reduction of cardiac function (within 48 hours of infusion), which may remain markedly reduced after nine months [31]. As the utility of rituximab continues to expand, physicians must be aware of this serious cardiovascular adverse effect. Interleukins, on the other hand, may cause hypotension associated with vascular leak syndrome and transient LV dysfunction may occur during infusion [14].

Cyclophosphamide: Cyclophosphamide is a nitrogen-mustard alkylating agent that has been shown to exhibit both potent immunosuppressive and immunomodulatory properties, and antineoplastic activity [34]. Its clinical use in anticancer therapy has been long-established [35] as well as it is a mainstay of most pretransplant preparative regimens including stem cell conditioning regimens [36]. The effect of cyclophosphamide on both cell-mediated and humoral immunity has made the drug appealing on the off-label treatment of several refractory autoimmune conditions [37-39]. Due to its variable use, cyclophosphamide's toxicity profile using distinctive dosing regimens has not been elucidated. Cyclophosphamideassociated haemorrhagic myocarditis has been documented in several studies, which show a typical course invariably leading to mortality [4043].

Although clinical presentation and severity varies, common signs and symptoms of cyclophosphamide-induced CM may include tachyarrhythmias, hypotension, heart failure, myocarditis, and pericardial disease, which typically present within the first 48 hours of drug administration but in some cases may be seen up to 10 days after therapy initiation [35]. Haemorrhagic myocarditis is a rare complication, which suggests poor prognosis and increased risk of acute death. The incidence of acute HF varies between $7 \%$ and $33 \%$ of patients receiving total dose more than $150 \mathrm{mg} / \mathrm{kg}$ cyclophosphamide. Cases of fatal cyclophosphamide-induced CM varies between $2 \%$ and $17 \%$ depending on different dosing regimens and patient populations. However, it is difficult to establish the true incidence due to reliance on case reports, which use variable doses and the drug is often administered in the presence of other cardiotoxic drugs [36,41,43-46].

Cyclophosphamide-induced CM lacks clearly defined predictive variables, which complicates the ability to stratify patients at a higher risk of the disease. However, cumulative dose is a well-recognized risk factor but without consensus regarding the threshold dose although $200 \mathrm{mg} /$ $\mathrm{kg}$ administered over 1 to 4 days is commonly employed in refractory cases of several autoimmune diseases [47]. Early studies reported considerable cardiotoxicity at doses $>270 \mathrm{mg} / \mathrm{kg}$ delivered over 1 to 4 days [48] or a dose per body surface area $\geq 1.55 \mathrm{~g} / \mathrm{m}^{2}$ [36]. Used in stem cells conditioning and refractory autoimmune conditions, significant cardiotoxicity has been demonstrated in doses as low as $100 \mathrm{mg} / \mathrm{kg}$ [43] . Other possible predictors of cyclophosphamide cardiotoxicity include advance age and the type of malignancy (lymphoma increases the risk more than breast cancer) [45], pre-existing risk factors for ischemic heart disease, prior or concomitant use of other cardiotoxins, a history of radiation therapy to mediastinum or left chest wall, and symptomatic HF $[45,46,49,50]$.

Tyrosine Kinase Inhibitors: Tyrosine kinase inhibitors (sunitinib and imatinib) are small molecule agents that inhibit cellular signalling involved in tumour cell angiogenesis and proliferation. These anticancer drugs improve anti-tumour activity and has fewer side effects. However, these drugs also affect tyrosine kinase regulating non-cancer functions resulting in undesirable side effects including $\mathrm{HF}$ and hypertension [14]. Sunitinib, a multi-targeted tyrosine kinase inhibitor, is approved by both the US and European Commission regulatory agencies for the treatment of renal cell carcinoma and gastrointestinal stromal tumours [51,52]. Analyses of drug efficacy demonstrate varying rates of cardiotoxicity ranging as high as $11 \%$ over a 3 -months followup period [14]. In a study of sunitinib-induced CM, Chu et al. [53] finds common cardiovascular events are moderate to severe HF, New York Heart Association (NYHA) functional class III-IV with a mean reduction of LVEF of 5\%. The risk of developing HF is increased by the presence of coronary disease although most cases of HF improved in terms of symptoms and LVEF after cessation of sunitinib therapy [53].

Imatinib is a small-molecule inhibitor that acts by selective blocking of the activity of tyrosine kinase [54,55]. It is widely used for the treatment of Philadelphia chromosome-positive leukaemia and gastrointestinal stromal tumours [56,57]. It is also a potential novel treatment option for pulmonary arterial hypertension [58], as well as a potent anti-inflammatory and anti-fibrotic drug, which is a promising candidate for the treatment of rheumatoid arthritis and systemic sclerosis $[59,60]$. Cardiac anatomy in imatinib-exposed rats demonstrates a dose-dependent restrictive type of remodelling and depressed hemodynamic performance not explained by myocardial fibrosis. Imatinib has been associated with reduced cardiac progenitor cell (CPC) depletion, reduced growth and increased cell death in both rat model and in humans. These findings suggest that cardiovascular side effects are the result of multiple actions of imatinib [61]. Risk factors for imatinib-induced CM have not been defined but congestive HF, pre-existing cardiac disease, coronary artery disease, hypertension and diabetes are common findings in patients exposed to imatinib [54]. Although imatinib might induced HF, the therapy requires careful monitoring starting immediately after initiation of therapy because HF has been detected as early as within the first weeks of treatment in some patients. The incidence of cardiotoxicity is very low and cardiotoxic side effects may occur preferentially in patients with pre-existing cardiac disease [54].

Pathophysiology: The pathophysiology of chemotherapyinduced CM has been described based on the inciting agent, mostly anthracyclines and trastumuzab [62-64]. The dominant proposed mechanisms for anthracycline-induced $\mathrm{CM}$ is the formation of anthracycline-iron complexes and the stimulation of free radical formation [65-68]. Human cardiomyocyte is susceptible to free radical damage due to relatively less superoxide dismutase and catalase activities, as well as anthracycline-associated suppression of glutathione peroxidase, which is the principle cardiomyocyte defence against freer radical damage [64]. The accumulation of superhydroxide free radicals leads to severe lipid peroxidation resulting into destruction of mitochondrial membranes, endoplasmic reticulum and nucleic acid $[69,70]$. A defective mitochondrial biogenesis and the formation of reactive oxygen species (ROS) mediated by topoisomerase-II beta is another frequently proposed pathologic mechanism [71]. Other possible mechanisms include reduced production of adenosine triphosphates, inhibited synthesis of nucleic acid and protein synthesis, impaired mitochondrial synthesis, induced myocyte apoptosis and increased immune functions [72,73].

The pathophysiologic mechanism for trastuzumab-induced $\mathrm{CM}$ is associated with the blockade of HER2 ${ }^{+}$receptor signals in cardiomyocytes [74]. The inhibition of HER2 ${ }^{+}$interferes with the usual repair mechanism of cardiomyocyte, which exacerbates myocyte apoptosis and necrosis [75]. For cyclophosphamide associated CM, 
suggested pathophysiologic mechanisms involve cyclophosphamide metabolites that cause oxidative stress and direct endothelial capillary damage with resultant extravasation of proteins, erythrocytes and toxic metabolites. The breakdown of endothelial cells in the presence of toxic metabolites directly damages the myocardium and capillary blood vessels leading to oedema, interstitial haemorrhage and formation of micro-thrombi. These insults manifest clinically as acute HF and arrhythmias [35].

Diagnosis: Current consensus guidelines define cardiotoxicity as LVEF decline $\geq 5 \%$ to $<55 \%$ with HF symptoms or an asymptomatic decrease of LVEF $\geq 10 \%$ during cancer therapy, although other LVEF cut-offs such as $<50 \%$ as a lower limit of normal have also been proposed [76,77]. Measurement of cardiac biomarkers should be used as a diagnostic tool to identify, assess and monitor cardiotoxicity. Troponin combined with longitudinal strain measurement is emerging as an important biomarker for prediction of cardiotoxicity of patients undergoing chemotherapy $[78,79]$. Acute anthracycline-induced CM consists of sinus tachycardia or ECG abnormalities such as non-specific ST-T wave changes, reduced QRS voltage, or QRS prolongation but these signs are non-specific [3].endomyocardial biopsy (EMB) is the most sensitive tool for diagnosing anthracycline-induced CM but it is not in routine use. However, newer echocardiographic techniques such as myocardial strain imaging are emerging as promising non-invasive modality for the early detection of cardiotoxicity during and after chemotherapy [3].

Management: The current management practices of chemotherapyinduced CM recommend a four-pronged approach: (a) pre-treatment assessment; (b) risk reduction; (c) surveillance and early treatment of cardiotoxicity during therapy; and (d) post-treatment surveillance $[3,21,76,77]$. The AHA/American College of Cardiology (ACC) [80] and the American Society of Clinical Oncology [81] have set guidelines for treatment alterations based on cardiac function and recommendation for cardioprotective therapies. Two major preventive measures are treatment modification and cardiac risk reduction through limiting cumulative anthracycline dose $\left(<550 \mathrm{mg} / \mathrm{m}^{2}\right)$, infusion delivered for six hours over bolus therapy, or concomitant use of cardioprotective agents such as such as dexrazoxane. Finally, the use of less cardiotoxic anthracycline analogues such as epirubicin and idarubicin have been used to minimize cardiotoxicity $[3,6,62,64]$. Cancer patients with systolic HF should be treated with guideline-directed medical therapy to improve cardiac function and relieve symptoms [3].

\section{Antiretroviral drugs}

Drugs: The first paediatric cases of HIV-associated CM were reported in the late 1980s and since then CM has become the leading non-infectious cause of death among HIV-infected children [82-85]. $\mathrm{HIV}$-associated CM has been classified as Centres for Disease Control (CDC) Category B condition and a World Health Organization HIV clinical stage 4 disease $[86,87]$. The annual incidence of HIV-associated $\mathrm{CM}$ has increased significantly since the introduction and widespread use of HAART (combined antiretroviral therapy). The annual incidence of HIV-induced CM in 2003, prior to the introduction of HAART was 15.9 per 1,000 individuals [88], and rose significantly to 176 per 1000 in 2014 after the introduction of HAART [89]. Individual antiretroviral drugs (zidovudine, didanosine or zalcitabine) have also been implicated as a possible cause of CM in HIV-positive patients [90-93].

Zidovudine: Zidovudine (azidothymidine: AZT) was the first nucleoside reverse transcriptase inhibitor (NRTI) to be developed and commercialized in 1987 for the treatment of symptomatic individuals infected with HIV or AIDS, and the next three compounds were didanosine in 1991, zalcitabine in 1992 and stavudine in 1994 [92-95]. Today, monotherapy with zidovudine is uncommon because HAART has proved a formidable clinical combination, which usually includes two NRTI drugs and HIV-1 protease inhibitor [96]. Zidovudine has been demonstrated to cause mitochondrial skeletal myopathy $[97,98]$. It is characterized by microscopic "ragged red fibres" and ultrastructural paracrystalline inclusion, and high lactate pyruvate ratio (consistent with abnormal mitochondrial function) seen in the blood of the patients with Zidovudine-induced mitochondrial myopathy $[99,100]$. Models of zidovudine-treated rats and transgenic (TG) AIDS mice also reveal CM and mitochondrial skeletal myopathy [101-105]. There is documented evidence of a relationship between the development of HIV/AIDS associated CM and prolonged treatment with zidovudine [106-108]. However, the mechanism is not completely understood but altered mtDNA replication, its resultant effect on energetics and related cellular processes has been proposed as a possible pathophysiologic mechanism [105].

Didanosine: Didanosine is a HIV nucleoside analogue reverse transcriptase inhibitor. The drug acts by preventing the formation of phosphodiester linkages required for the completion of nucleic acid chains. Thus, it is a potent inhibitor of HIV replication, acting as a chain-terminator of viral DNA by binding to reverse transcriptase [89]. NRTIs, which are the backbone of HAART, have been associated with mitochondrial toxicity, on development of CM in symptomatic HIV-infected children $[89,109]$. However, the cardiotoxic effect of didanosine alone has not been determined in HIV-positive patients since in HAART it is often used in combination with other NRTIs mostly zidovudine [102]. Domanski et al. [110] retrospectively reviewed echocardiograms, clinical records and laboratory data from 137 HIV-infected children who were receiving either zidovudine or didanosine, both drugs or no antiretroviral therapy. The odds that CM would develop was 8.4 times greater in children receiving zidovudine than those who had never received the drug while didanosine was no associated with the development of CM [110]. In a post-hoc analysis of 33,347 patients from the DAD study, didanosine increased the rate of myocardial infarction compared with those with no recent use of the drug (relative rate: $1.90 ; 95 \%$ CI 1.47-2.45; $\mathrm{p}=0.0001$ ). The risk was not explained by the underlying risk factors and seemed to disappear beyond six months after drug cessation [111]. Currently, there is no sufficient evidence suggesting the role of didanosine in HAART in the development of CM in HIV-infected patients.

Zalcitabine: Zalcitabine is an analogue of the nucleoside deoxycytidine which, when intracellularly converted to an active triphosphate metabolite, inhibits replication of human immunodeficiency virus (HIV) [112]. Zalcitabine is perceived to act in the early phase of HIV replication by inhibiting reverse transcriptase and terminating the viral DNA chain $[112,113]$. A prospective cohort study of 3,035 perinatally HIV-infected patients enrolled in a US-based multicentre trial between 1993 and 2007 identified 99 cases of CM [109]. While HAART was associated with 50\% lower incidence of CM compared to no HAART, zalcitabine was associated with $80 \%$ higher incidence of CM. Factors independently associated with a higher rate of CM included older age at HAART initiation, zalcitabine use before HAART initiation and HAART regime containing zidovudine. CM was associated with a six-fold higher mortality rate [109]. In a double-blind phase II trial comparing zalcitabine in combination with zidovudine and zidovudine monotherapy in 250 clinically stable, previously zidovudine treated, HIV-infected children, Bakshi et al. [114] found higher cardiotoxicity in combination therapy ( 2 with $\mathrm{CM}$ ) than in 
zidovudine monotherapy (none with $\mathrm{CM}$ ). However, more deaths were recorded with zidovudine monotherapy (10) compared to combination therapy (4) but the difference was not significant (log-rank test, $\mathrm{p}=0$ .083). Despite this evidence, there are no studies specifically examining cardiotoxicity of zalcitabine in HIV-infected individual and its pathophysiologic mechanisms the development of CM remains unclear.

Pathophysiology: The key pathophysiologic mechanism of antiretroviral-induced CM is mitochondrial toxicity induced by longterm exposure to NRTI - the key drug in HAART $[103,105,115]$. NRTIs works by inhibiting HIV reverse transcriptase but also inhibits DNA polymerase gamma, the enzyme responsible for mitochondrial DNA (mtDNA) replication $[103,105,115-120]$. The inhibitory effect of NRTIs on DNA polymerase gamma varies across different human tissues [116120]. The effect of NRTIs on mitochondrial varies across the individual drugs. It is relatively consistent with zalcitabine, which is rarely used or no longer in use in some clinical settings, causing the greatest degree of toxicity, followed by didanosine, stavudine and zidovudine [116-120]. On the other hand, lamivudine, abacavir and tenofovir drugs have relatively limited toxic effect on mitochondria [116,117]. However, a recent adult study did not find an association between current abacavir and LV hypertrophy [121].

Diagnosis: On HIV-infected patients receiving HAART therapy, diagnosis of $\mathrm{CM}$ is based on evidence of cardiac dysfunction and mitochondrial toxicity. Cardiac dysfunction is diagnosed based on the presence of ventricular diastolic or systolic dimensions $\geq 2$ standard deviations above the mean for body surface area or abnormal fractional shortening index $\leq 2$ standard deviations below the mean [109]. The gold standard for diagnosis of mitochondrial toxicity is examination of biopsy specimen from muscles, liver or nerve but the collection of these biopsy specimens is not practical especially for vulnerable children [120]. On the other hand, peripheral blood mononuclear cells (PBMCs) are easily obtained from patients, and several reports suggest a clinical correlation between toxicity and mtDNA levels in the PBMCs of HIVinfected adults receiving antiretroviral therapies [122-126]. However, several studies have also shown no correlation between mtDNA levels in PBMCs and lipodystrophy, lactate levels or the toxicities of antiretroviral regimens [127-132]. The clinical utility of assays for mtDNA levels in PBMCs is still controversial $[133,134]$. Thus, more research is warranted to elucidate the importance of mtDNA levels in PBMCs in the clinical setting, especially for children with limited sample materials [109].

Management: There is no proved strategies for treatment of CM associated with the use of antiretroviral therapy. However, the timing and choice of therapy have been associated with lower rates of CM. In a study of the impact of HAART on CM among children and adolescent perinatally infected with HIV-1, Patel [109] found a strong protective association of HAART on the development CM. Early initiation of HAART was associated with lower incidence of CM revealing the benefits of maintaining immunocompetence early. In choosing the most appropriate therapy (with reduced risks of $\mathrm{CM}$ ), the benefits of specific medication must be weighed against their potential toxicities [109]. Children receiving didanosine-containing antiretroviral regimens register the lowest mtDNA levels in PBMCs and are the greatest risk for long-term adverse effects of mitochondrial toxicity, which is the major pathophysiology of $\mathrm{CM}$ in $\mathrm{HIV}$-infected patients receiving HAART [120].

\section{Chloroquine}

Chloroquine and its derivatives such as hydroxychloroquine are not only efficient in treating malaria but are also frequently used in the treatment of rheumatoid arthritis, sarcoidosis, and systemic lupus erythematous [135]. Although chloroquine is known to cause a variety of toxic effects including retinopathy, neuropathy and myopathy, its cardiotoxicity is not generally appreciated. Its common cardiotoxic effects include conduction disturbances such as bundle branch block and biventricular hypertrophy with restrictive CM [136]. In a case report of 81-year old female with rheumatoid arthritis treated intermittently with chloroquine for over 25 years hospitalized for acute right HF, physical examination revealed bilateral lower extremity oedema and hepatomegaly and ECG tests revealed sinus rhythm at $58 \mathrm{bpm}$, left anterior fascicular block, and left and right ventricular hypertrophy. On echocardiogram, the patient had hypertrophic CM with hypokinesis, left atrial and right ventricular dilatation. She developed complete heart block on the twelfth day, pacemaker was implanted but dies from low output syndrome on the sixteenth day of hospitalization [136].

Pathophysiology: The pathophysiologic mechanisms of chloroquine-induced CM remains poorly understood but emerging evidence suggest the involvement of direct lysosomal dysfunction through the inhibition of lysosomal enzymes resulting in lysosomal storage disorders resulting into significant cardiac manifestations including $\mathrm{CM}$ with concentric hypertrophy and conduction disorders and ultimately HF $[137,138]$. Pathologic metabolic products can be seen in ultrastructural histology as pathognomonic cytoplasmic inclusion bodies [138]. Bi-atrial dilation has been described in chloroquine-induced CM and likely reflects the degree and duration of diastolic dysfunction and elevated filling pressures in the setting of HF with preserved ejection fraction [135]. Although rare, severe and irreversible cases of cardiac dysfunction have been reported involving conduction disturbances (bundle-branch block, atrioventricular block) and $\mathrm{CM}$ often with hypertrophy, restrictive physiology and congestive heart failure [135].

Diagnosis: Due to unspecific clinical features of chloroquineassociated cardiotoxicity, the identification and follow-up of potentially affected patients is essential. Definitive diagnosis of this toxic storage disease is based on histological and non-invasive examination of the myocardium in conjunction with electron microscopy [138]. Regular screening with 12-lead ECG and transthoracic echocardiography should be considered for detecting conduction system abnormalities and/or biventricular structural and functional alterations. Cardiac magnetic resonance imaging and endomyocardial biopsy are valuable tools to provide prognostic insights and confirm the diagnosis of chloroquine-induced CM [138].

Management: Clinical management of chloroquine-induced CM lacks proven therapies and thus clinical monitoring and early recognition of cardiotoxicity is an important management strategy in patients undergoing chronic chloroquine therapy. Immediate treatment cessation is essential if toxicity is suspected because of the early reversibility of CM. withdrawal of treatment has been associated with HF symptoms resolution (NYHA functional class I) and normalized biventricular structure and function with moderately enlarged left atrium and mild tricuspid regurgitation on cardiac MRI [135]. Finally, due to lower levels of cardiotoxicity, hydroxychloroquine is predominantly used today [138].

\section{Antipsychotic drugs}

Antipsychotic Agents: The use of antipsychotic drugs has expanded to include multiple mental health conditions beyond schizophrenia, which has increased the overall population exposed to these medications associated with adverse cardiovascular effects. Antipsychotic 
(neuroleptic) $\mathrm{CM}$ is a serious complication of psychotropic therapy caused by cardiotoxicity of antipsychotic preparations. Antipsychotic $\mathrm{CM}$ belongs to secondary causes of dilated $\mathrm{CM}$ characterized by diffusion myocardial damage, decreased cardiac contractility and heart failure [139]. Although several antipsychotic drugs have been associated with adverse metabolic and cardiovascular effects, only phenothiazines and clozapine have been directly implicated as a primary cause of druginduced CM.

Phenothiazines: Phenothiazines (such as chlorpromazine and promethazine) are classified as a major class of antipsychotic drugs widely used as a premedicant to induce a state of tranquillity, calmness, or to diminish anxiety or stress in patients diagnosed with schizophrenia and bipolar disorders [140,141]. Their main pharmacologic activity results from the blockade of dopamine 1-2 receptors within the mesolimbic dopamine pathway [141,142]. Recently, some of these phenothiazines have been found to exhibit anti-tumour activities including those mediated by protein kinase $\mathrm{C}$, calmodulin-dependent enzymes, P-glycoprotein, and protein phosphatase 2A [143]. In addition to their anti-dopamine activities, phenothiazines can block histamine and cholinergic muscarinic receptors leading to sedation, suppression of oral secretions, tachycardia, urinary retention and constipation [144]. Many cases of phenothiazine-induced CM have been reported in Russia. In an analysis of 830 autopsy protocols and medical histories of schizophrenic patients who died between 1952 and 2007, dilated CM was found to occur much more frequently than in the study of analogous material from the general population. The difference was attributed to prolonged neuroleptic therapy with phenothiazine preparations in schizophrenics confirmed by their significantly smaller heart mass compared with the mass in the period prior treatment. The frequency of dilated CM increased with the duration of therapy [144]. In a review of 65 schizophrenic patients after long-term treatment with phenothiazine, cases of dilated CM were $2 \%$ of all autopsies or significantly higher than the general incidence of dilated CM. There was evidence of slightly lower heart mass due to cardiovascular hypoplasia [145].

Clozapine: Clozapine is the first atypical antipsychotic drug clozapine (Clozaril) drug approved for the treatment of resistant schizophrenia - when other antipsychotic drugs either have not worked or have caused severe side effects. It is atypical because it lacks typical extrapyramidal side effects of antipsychotic drugs [146]. Despite its treatment effectiveness, numerous cases of myocarditis have been reported in schizophrenic patients receiving clozapine [147-149]. Post-marketing experience suggests an increased risk of myocarditis presenting commonly within the first two weeks after treatment initiation. CM has also been reported, generally occurring later in the treatment and in some cases fatal [148]. Tachycardia is a common side effect of clozapine treatment seen in $25 \%$ of the cases, especially during dose titration in early treatment. For patients on clozapine treatment with persistent tachycardia at rest, especially in the first two months of clozapine treatment, monitoring for other signs and symptoms of myocarditis and CM is essential [148].

Pathophysiology: The pathophysiologic mechanism of CM associated with antipsychotic drugs is not sufficiently developed but it is suggested to be triphasic:

a) The latent phase, which is clinically completely compensated;

b) The developed phase marked by cardiac violations manifests but without symptoms of congestive HF; and c) The terminal phase marked by symptomatic congestive HF. [150153].

Lethal outcomes in the latent and developed phases result from intercurrent diseases or sudden cardiac death of arrhythmogenic genesis $[151,153,154]$, observed in $44 \%$ of autopsy cases of antipsychotic drugrelated CM $[155,156]$. In the terminal phase, progressive congestive HF is an intermediate cause of death $[151,153,154]$. CM develops slowly and initially it is subclinical and hardly noticeable.

In the latent stage, $\mathrm{CM}$ is either asymptomatic or presents with non-specific symptoms although fatigue and shortness of breath, and tachycardia are common symptoms on presentation of neuroleptics and ECG abnormalities include diffusion muscular changes, different types of violation of conductivity, left axis deviation, right heart overload and LV hypertrophy [150,154,157-159]. In the developed phase, symptoms of CM become apparent but that of HF remain unclear. Patient complaints become certain - weakness, fatigue, exertional dyspnoea at moderate physical activity and chest pain. Physical examination reveals deafness of cardiac sounds, some expansion of the borders of a heart, tachycardia and breathlessness. In the terminal phase, symptoms of HF become apparent: dyspnoea at rest or during exertion, orthopnoea, increased liver, peripheral and cavitary oedema, deafness of cardiac sounds, tachycardia, and an arrhythmia, moderate arterial hypertension and increased arterial pressure [151,154]. On ECG, observed changes include violation of conductivity, prolonged QT interval, and right heart overload [150,157-159]. Special attention should be given to monitoring QTc since it is an independent indicator of conditions of a decompensation HF [160].

Diagnosis: Clinical diagnostic of CM associated with antipsychotic drugs is difficult because of heterogeneous and non-specific symptoms. Volkov [98] after a series of studies on antipsychotic CM and a multidisciplinary team including individuals with specialized expertise in cardiology and pharmacology using 116 reports of myocarditis submitted to the Australian Therapeutic Good administration developed the following diagnostic criteria for antipsychotic CM $[140,148]$.

\section{Major criteria (absolute)}

a) Onset of new symptoms within 45 days of commencing therapy; and

b) The presence of other cardiac pathology - histological evidence of myocarditis at post-mortem or myocardial biopsy in the absence of other plausible explanations or exposure to other likely causative agents; OR

c) New signs of cardiac dysfunction such as persistent tachycardia (heart rare $>100$ beats per minute $\geq 24$ hours, third heart sound, basal crepitations, peripheral oedema) with or without febrile systemic illness.

\section{Minor Criteria (relative, with or without eosinophilia)}

a) Elevated troponin 1 and/or troponin T levels ( $\geq 2$ times the upper limit of normal);

b) Elevated CK-MB levels ( $\geq 2$ times the upper limit of normal);

c) ECG abnormalities ( $\geq 1 \mathrm{~mm}$ ST segment depression or T-wave inversion in 2 or more contiguous leads, excluding lead VR consistent with myocarditis with no other obvious cause);

d) Chest X-ray evidence of HF;

e) Non-invasive evidence of LV/RV systolic dysfunction; 
f) Sudden cardiac death (for posthumous diagnosis).

Based on case series, diagnostic criteria of antipsychotic should include at least two major criteria and at least one minor criteria must be present. Long-term treatment with antipsychotic drugs should be the main factor raising clinical suspicion for CM. However, additional research and accumulation of practical experience is warranted to confirm these diagnostic criteria although it may be useful for early identification of this serious complication of antipsychotic therapy in order to institute timely corrective treatment [140].

Management: At present, there is no specific treatment of antipsychotic CM. Monitoring protocol is recommended for the first four weeks of initiation of therapy to detect myocardial changes. The protocol should include baseline measurement of troponin and C-reactive protein, echocardiography and vital signs every two days for 4 weeks, and serial measurement of troponin and C-reactive protein weekly for 4 weeks $[147,148]$. Monitoring of eosinophilia as the condition does not occur in all patients [148]. For all patients with suspected myocarditis or DCM, the most effective treatment strategy is immediate and permanent discontinuation for all patients $[161,162]$. However, for clozapine cardiotoxicity, therapy discontinuation presents a therapeutic challenge since clozapine is indicated for patients with refractory schizophrenia. Some case reports have described a successful rechallenge with clozapine started with low doses and progress with slow dose titration and frequent monitoring of both troponin and cardiac function [162,162]. All clinicians caring for patients receiving antipsychotic drugs should be aware of this rare but potentially fatal cardiac adverse effect. Monitoring protocols or symptom questionnaire may help in the early detection and treatment of antipsychotic CM especially in the first four weeks of therapy. Any patients exhibiting symptoms of myocarditis or DCN should immediately undergo cardiac assessment [140,148].

\section{Meta-analysis of diagnosis and management}

The efficacy of several drugs including anti-cancer, antiretroviral and antipsychotic have been undermined by the risk of cardiotoxicity and drug-induced CM. Early diagnosis, treatment and monitoring are essential to detect and manage cardiotoxicity in patients receiving these drugs and reduce the risk of developing HF. This meta-analysis, which includes both clinical trials and cohort studies, seeks to estimate the event (incidence) rate of echocardiography and ECG abnormalities associated with drug-induced cardiotoxicity and CM, and the efficacy of dose modulation (or cessation) and cardioprotective adjuvants in protecting against cardiotoxicity. Online databases MEDLINE, EMBASE and the Cochrane Library were searched for relevant studies with no restriction on publication date, language and type of study. Clinical outcome of interest were ECG and echocardiographic changes, changes in strain rate, and the efficacy of cardioprotection as a prophylaxis against cardiotoxicity, the development of CHF and cardiac-associated deaths. Tables 2 and 3 provide a summary of the 39 studies included in this meta-analysis.

\section{Findings}

Study characteristics: Thirty-nine (39) studies [148,163-200] published between 1975 and 2018, and investigated the diagnosis and/ or treatment of CM due to acute or long-term exposure to medically prescribed cardiotoxic drugs were included in this meta-analysis. In total, 3,069 patients were enrolled. Twenty-seven (27) studies [148,163188] enrolling 1,456 patients (mean age $=47.4$ years, range $11.1-74.0$ ) evaluated ECG and echocardiographic diagnostic features of drug- induced CM using ECG/echo ( $\mathrm{n}=719$ patients) $[148,163-188]$ and myocardial strain imaging ( $\mathrm{n}=737$ patients) [172-188]. The remaining 12 studies [189-200] enrolling 1,613 patients randomized into treatment $(n=729)$ and control or placebo $(n=884)$ evaluated the efficacy of cardioprotective adjuvants as prophylaxis against cardiotoxicity, CHF or death. Nearly all the included studies evaluated CM associated with anti-cancer treatment [166-200], while the remaining three evaluated $\mathrm{CM}$ associated with antipsychotic drugs (phenothiazines or clozapine) $[148,163,164]$ or antiretroviral drugs (zidovudine and nevirapine) [165]. The most common cardioprotective adjuvant evaluated was dexrazoxane [190,191,195], followed by statin [197,198], and the traditional HF drugs (ACE-I and/or beta-blocker) $[193,194,196,199,200]$. One study by Georgakopoulos et al. [196] evaluated cardioprotective effect of two drugs (metoprolol and enalapril) on lymphoma patients treated with doxorubicin, in which each outcome was treated separately in the pooled analysis. The major cardioprotective outcomes evaluated in the pooled analysis was cardiotoxicity, CHF and deaths.

\section{Study Outcomes: ECG and Echocardiography Evidence}

Diagnosis of drug-related cardiotoxicity and CM usually is based on abnormalities in ECG and echocardiographic findings. Table 4 provides a summary of the pooled analysis of event rate of ECG and echocardiography findings. Pooled analysis of five studies [165$169,171]$ show 155 patients out of 478 had echocardiographic evidence of ventricular dysfunction (event rate: $32.8 \%$; $95 \%$ CI: $20.5 \%$ to $48.2 \%$; $p$ $=0.029$ ) while in three studies $[148,163,169], 94$ out of 185 patients had evidence of ECG abnormalities (event rate: $66.3 \%$; $95 \%$ CI: $34.4 \%$ to $88.0 \% ; p=0.316$ ) but the rate was not statistically significant. The most common echocardiography evidence of cardiotoxicity or CM was LV hypertrophy (event rate: $31.1 \%$; $95 \%$ CI: $8.6 \%$ to $68.4 \%$ ) while the most common ECG abnormalities were T-wave changes (event rate: $44 \%$; 95\% CI: $8 \%$ to $87.6 \%$ ), ST changes (event rate: $22.9 \%$; $95 \%$ CI: $7.6 \%$ to $51.8 \%$ ) and tachycardia (event rate: $0.274 ; 95 \%$ CI: 0.076 to 0.632 ). Cases of deaths were at $14.4 \%$ (95\% CI: $5.1 \%$ to $34.5 \%$; $p=0.002$ ). Finally, pooled analysis of nine studies [172,174-178,181,187,188] enrolling patients with normal LVEF receiving anticancer therapy showed non-significant changes in weighted mean differences of LVEF (WMD: -1.04; 95\% CI: -2.15 to $-0.069 ; \mathrm{p}=0.066$ ) (Figure 1).

Myocardial Strain Imaging: Pooled analysis of the global systolic myocardial strain (myocardial deformation), evaluated using speckle tracking echocardiography (STE) or tissue Doppler imaging (TDI) sought to evaluate echocardiographic evidence for the diagnosis of the sub-clinical stage of drug-induced CM. Pooled analysis of 12 studies [173,176-181,184-188] on weighted mean difference (WMD) of global longitudinal strain (GLS) pre and post-anticancer therapy reveals a significant deterioration of GLS (WMD: -1.503 ; 95\% CI: -2.028 to -0.978 to; $p=0.000$ ) (Figure 2). Similarly, a pooled analysis of four trials $[172,174,175,183]$ showed a significant deterioration in LSR (WMD: -0.374 ; 95\% CI: -0.491 to $-0.256 ; p=0.000$ ) (Figure 3). Pooled analysis of five studies $[173,175,176,181,184]$ showed a significant decrease in radial strain (RS) (WMD: -5.92 ; $95 \%$ CI: -10.1 to -1.58 ; $p=0.05$ ) (Figure 4).

Cardioprotective adjuvants: Anthracycline dose modulation or cessation was associated with improved cardiac function and the reduction or elimination of cardiotoxicity [163-167] but there was insufficient data provided for a meta-analysis. Pooled analysis of nine (9) clinical trials [189-194,196,197,199] revealed a combination therapy of anti-cancer drugs and cardioprotective adjuvants shows a positive trend towards reduced risk of cardiotoxicity (Odds Ratio [OR]: 0.344; 
Table 2. Summary of studies included in the meta-analysis

\begin{tabular}{|c|c|c|c|c|c|c|}
\hline Author & Year & No. & Age (yrs.) & Drug(s) & Test & Summary of main Findings \\
\hline Ronaldson [148] & 2018 & 38 & $38 \pm 13$ & AP (Clozapine) & Biomarkers & $\begin{array}{l}\text { Eosinophil counts are non-specific but elevated c-reactive protein may be an early indicator } \\
\text { of developing myocarditis during the first four weeks of therapy. }\end{array}$ \\
\hline Raj [163] & 1975 & 140 & $36(20-60)$ & AP (Phenothiazines) & $\begin{array}{l}\text { ECG, clinical } \\
\text { signs }\end{array}$ & $\begin{array}{l}\text { ECG abnormalities (T-wave changes, } \mathrm{ST} \text { depression, } \mathrm{PR} / \mathrm{QT} \text { prolongation, sinus tachycardia } \\
\text { and right bundle branch) are common but disappear after treatment cessation. }\end{array}$ \\
\hline Kilian [164] & 1999 & 8 & $38.3(22-52)$ & AP (Clozapine) & $\begin{array}{l}\text { ECG, clinical } \\
\text { signs }\end{array}$ & $\begin{array}{l}\text { Clozapine therapy may be associated with potentially fatal myocarditis and cardiomyopathy } \\
\text { in physically healthy young adults with schizophrenia }\end{array}$ \\
\hline Majonga [165] & 2010 & 201 & $11.1(9-12)$ & $\begin{array}{l}\text { ART (Zidovudine, } \\
\text { nevirapine) }\end{array}$ & ECG, echo & $\begin{array}{l}\text { HIV-infected children on ART have a high burden of echo abnormalities. Right heart } \\
\text { disease may be part of a global cardiomyopathic process. }\end{array}$ \\
\hline Gottdiener [166] & 1981 & 32 & -- & Anthracycline & ECG, echo & $\begin{array}{l}\text { Depressed ECG voltage and systolic LV function are common but do not necessarily predict } \\
\text { clinical cardiac deterioration. }\end{array}$ \\
\hline Steinherz [167] & 1981 & 40 & -- & Anthracycline & ECG & $\begin{array}{l}\text { High dose cyclophosphamide is associated with ECG abnormalities and increases the risk } \\
\text { of cardiomyopathy in children within one week of therapy }\end{array}$ \\
\hline Godoy [168] & 1997 & 120 & -- & Anthracycline & ECG, Echo & $\begin{array}{l}\text { Non-invasive tests such as echocardiography and ECG still play the main role for serial } \\
\text { cardiac monitoring in young children. }\end{array}$ \\
\hline Dazzi [169] & 2001 & 7 & 41 & Anthracycline & $\begin{array}{l}\text { ECG, autopsy } \\
\text { analysis }\end{array}$ & $\begin{array}{l}\text { ECG cannot detect subclinical ANT-cardiotoxicity. Awareness of acute adverse effects on } \\
\text { cardiac performance by ANT facilitates early recognition and prevention and HF. }\end{array}$ \\
\hline Zver [170] & 2007 & 23 & & Cyclophosphamide & $\begin{array}{l}\text { Biomarkers, } \\
\text { ECG, Echo }\end{array}$ & $\begin{array}{l}\text { Elevated BNP and endothelin-1 levels are sensitive indicators of myocardial injury and } \\
\text { diastolic functional parameters may be sensitive predictors of early cardiotoxicity. }\end{array}$ \\
\hline Shaikh [171] & 2013 & 110 & $74 \pm 44$ & $\begin{array}{c}\text { Doxorubicin } \pm \\
\text { daunorubicin }\end{array}$ & Echo & $\begin{array}{l}\text { Incidence of anthracycline-induced cardiotoxicity is high. Long-term follow-up is essential } \\
\text { to diagnose its late manifestations. }\end{array}$ \\
\hline Mercuro [172] & 2007 & 16 & $56 \pm 3$ & Epirubicin & TDI & $\begin{array}{l}\text { Early myocardial impairment affects LV systolic rather than diastolic function during early } \\
\text { contractility during epirubicin treatment. }\end{array}$ \\
\hline Jurcut [173] & 2008 & 16 & $69.8 \pm 3.1$ & Dox & TDI & $\begin{array}{l}\text { Myocardial deformation parameters detect subtle changes in longitudinal and radial LV } \\
\text { function and should be used for cardiac function monitoring during DOX chemotherapy. }\end{array}$ \\
\hline Mantovani [174] & 2008 & 31 & $59 \pm 14$ & Epirubicin & TDI & $\begin{array}{l}\text { A reduction in the strain rate (SR) peak indicates significant impairment in systolic LV } \\
\text { function at cumulative epirubicin dose of } 200 \mathrm{mg} / \mathrm{m}^{2} \text {. }\end{array}$ \\
\hline Wildiers [175] & 2008 & 16 & $69(65-74)$ & Dox & TDI & $\begin{array}{l}\text { Doppler-based regional myocardial functional assessment documents subtle changes } \\
\text { before conventionally indices (LVEF) and might be useful for early initiation of preventive } \\
\text { measures. }\end{array}$ \\
\hline Fallah-Rad [176] & 2011 & 42 & $47 \pm 9$ & Trastuzumab & TDI & $\begin{array}{l}\text { Tissue velocity and strain imaging are able to detect pre-clinical changes in LV systolic } \\
\text { function before conventional changes in LVEF occur. }\end{array}$ \\
\hline Sawaya [177] & 2011 & 43 & $47 \pm 11$ & ANT, trastuzumab & TDI & $\begin{array}{l}\text { Cardiac troponin plasma concentrations and longitudinal strain may predict the development } \\
\text { of cardiotoxicity. }\end{array}$ \\
\hline Stoodley [178] & 2011 & 52 & $49 \pm 9$ & ANT & STE & $\begin{array}{l}\text { Decreased LV systolic strain immediately after anthracycline treatment may indicate early } \\
\text { impairment of myocardial function before detectable changes in LVEF }\end{array}$ \\
\hline Al-Biltagi [179] & 2012 & 25 & $9 \pm 2.6$ & Dox & STE & $\begin{array}{l}\text { 2-D longitudinal strain echocardiography is more sensitive than conventional 2-D and TDI } \\
\text { in detecting early LV doxorubicin-induced cardiotoxicity in children }\end{array}$ \\
\hline Poterucha [180] & 2012 & 19 & -- & ANT & STE & $\begin{array}{l}\text { Changes in 2D LV GLS precede decreases in LVEF or predicts an increased likelihood that } \\
\text { depressed LVEF will occur later }\end{array}$ \\
\hline Sawaya [181] & 2012 & 81 & $50 \pm 10$ & $\begin{array}{l}\text { ANT, trastuzumab, } \\
\text { taxanes }\end{array}$ & TDI & $\begin{array}{l}\text { Systolic longitudinal myocardial strain and ultrasensitive troponin I may be useful markers } \\
\text { for predicting subsequent cardiotoxicity and helping guide treatment to avoid cardiac side- } \\
\text { effects }\end{array}$ \\
\hline Stoodley [182] & 2012 & 52 & $49 \pm 9$ & Dox, Epirubicin & STE & $\begin{array}{l}\text { Changes in LV diastolic function immediately after the administration of anthracycline are } \\
\text { associated with reduced systolic function. }\end{array}$ \\
\hline Zhang [183] & 2012 & 60 & $51 \pm 7$ & $\begin{array}{l}\text { Epirubicin }(200 \mathrm{mg} / \\
\mathrm{m} 2)\end{array}$ & TDI & $\begin{array}{l}\text { TDI is a useful tool to show epirubicin-induced early LV regional systolic dysfunction in } \\
\text { patients with breast cancer. }\end{array}$ \\
\hline Baratta [184] & 2013 & 36 & $47 \pm 16$ & Dox, trastuzumab & STE & $\begin{array}{l}\text { 2D systolic LS and RS were useful to predict mild ventricular systolic dysfunction in } \\
\text { chemotherapy-treated patients }\end{array}$ \\
\hline Negishi [185] & 2013 & 81 & $50 \pm 11$ & Dox, Epirubicin & STE & $\begin{array}{l}\text { GLS is an independent early predictor of later reductions in EF and incremental to usual } \\
\text { predictors in patients at risk for trastuzumab-induced cardiotoxicity. }\end{array}$ \\
\hline Stoodley [186] & 2013 & 78 & $52 \pm 10$ & ANT & STE & $\begin{array}{l}\text { Myocardial strain imaging is more sensitive than LVEF for the early detection and } \\
\text { intermediate term monitoring of LV systolic function in ANT patients and may aid in the } \\
\text { development of improved monitoring protocols }\end{array}$ \\
\hline Emren [187] & 2015 & 40 & $50 \pm 10$ & Trastuzumab & STE & $\begin{array}{l}\text { Trastuzumab therapy is associated with subclinical LV dysfunction as early as } 7 \text { days after } \\
\text { initiation of the therapy as evidenced by the decreases in GLS value of LV }\end{array}$ \\
\hline Gripp [188] & 2018 & 49 & $49.7 \pm 12$ & ANT, trastuzumab & TDI & $\begin{array}{l}\text { STI allow the early identification of patients who could develop anthracycline and/or } \\
\text { trastuzumab-induced cardiotoxicity }\end{array}$ \\
\hline
\end{tabular}

2D: Two Dimensional; ANT: Anthracyclines; ART: Anti-Retroviral Therapy; AP: Antipsychotic; CM: Cardiomyopathy; LVDD: Left Ventricular Diastolic Dysfunction; LVH: Left Ventricular Hypertrophy; ULN: Upper Limit of Normal; ESR: Early Strain Rate (S-1); GLS: Global Longitudinal Strain; STE: Speckle Tracking Echocardiography; TDI: Tissue Doppler Imaging 
Table 3. Summary of studies on cardioprotective adjuvants and anti-cancer therapy

\begin{tabular}{|c|c|c|c|c|c|c|}
\hline First Author & Year & No. & Anticancer Drug & $\begin{array}{l}\text { Cardioprotective } \\
\text { Drug }\end{array}$ & $\begin{array}{l}\text { Cardiotoxicity } \\
\text { Outcomes }\end{array}$ & Summary of main findings \\
\hline Milei [189] & 1987 & 26 & Adriamycin & Prenylamine & Death, $\Delta$ LVEF & $\begin{array}{l}\text { Simultaneous administration of prenylamine may mitigate adriamycin-induced } \\
\text { cardiotoxicity }\end{array}$ \\
\hline Speyer [190] & 1992 & 150 & $\begin{array}{l}\text { Fluorouracil, } \\
\text { doxorubicin, } \\
\text { cyclophosphamide }\end{array}$ & ICRF-187 & CHF, $\triangle \mathrm{LVEF}$ & $\begin{array}{l}\text { By protecting against cumulative doxorubicin-induced cardiotoxicity, ICRF-187 } \\
\text { permits significantly greater doses of doxorubicin to be administered to patients with } \\
\text { greater safety }\end{array}$ \\
\hline Venturini [191] & 1996 & 160 & Epirubicn & Dexrazoxane & $\triangle \mathrm{LVEF}$ & $\begin{array}{l}\text { Dexrazoxane protects against epirubicin-induced cardiotoxicity and does not affect the } \\
\text { clinical activity and the non-cardiac toxicity of epirubicin. }\end{array}$ \\
\hline Silber [192] & 2004 & 135 & Enalapril & Placebo & Deaths, $\Delta$ LVEF & $\begin{array}{l}\text { Enalapril treatment reduced LV-end systolic wall stress in intermediate term for patients } \\
\text { exposed to anthracycline therapy. }\end{array}$ \\
\hline Cardinale [193] & 2006 & 114 & Enalapril & ACE-I & $\triangle \mathrm{LVEF}$ & $\begin{array}{l}\text { In high-risk, anthracycline-treated patients early treatment with enalapril seems to } \\
\text { prevent the development of late cardiotoxicity }\end{array}$ \\
\hline Kalay [194] & 2006 & 50 & Anthracycline & Carvedilol & Deaths, $\Delta$ LVEF & $\begin{array}{l}\text { Prophylactic use of carvedilol in patients receiving anthracycline may protect both } \\
\text { systolic and diastolic functions of the left ventricle }\end{array}$ \\
\hline Marty [195] & 2006 & 164 & Anthracycline & Dexrazoxane & $\mathrm{CHF}$ & $\begin{array}{l}\text { Dexrazoxane significantly reduced the occurrence and severity of anthracycline- } \\
\text { induced cardiotoxicity in patients at increased risk of cardiac dysfunction due to } \\
\text { previous anthracycline treatment without compromising the antitumor efficacy of the } \\
\text { chemotherapeutic regimen }\end{array}$ \\
\hline $\begin{array}{l}\text { Georgakopoulos } \\
{[196]}\end{array}$ & 2010 & 82 & Doxorubicin & Metoprolol & Deaths, $\Delta$ LVEF & Metoprolol does not reduce the risk of cardiotoxicity in patients treated with doxorubicin \\
\hline $\begin{array}{l}\text { Georgakopoulos } \\
{[196]}\end{array}$ & 2010 & 83 & Doxorubicin & Enalapril & Deaths, $\Delta$ LVEF & Enalapril does not reduce the risk of cardiotoxicity in patients treated with doxorubicin \\
\hline Acar [197] & 2011 & 40 & Anthracycline & Statin & $\triangle \mathrm{LVEF}$ & $\begin{array}{l}\text { Prophylactic use of atorvastatin could be effective in the maintenance of LVEF in } \\
\text { patients treated with anthracycline }\end{array}$ \\
\hline Seicean $[198]$ & 2012 & 201 & Anthracycline & Statin & Deaths, CHF & $\begin{array}{l}\text { Female patients with breast cancer treated with anthracycline chemotherapy, the use of } \\
\text { statin is associated with a lower risk for incident HF }\end{array}$ \\
\hline Bosch [199] & 2013 & 90 & Anthracycline & $\begin{array}{c}\text { Enalapril }+ \\
\text { carvedilol }\end{array}$ & $\triangle \mathrm{LVEF}$ & $\begin{array}{l}\text { Combined treatment with enalapril and carvedilol may prevent LVSD in patients with } \\
\text { malignant hemopathies treated with intensive chemotherapy }\end{array}$ \\
\hline Seicean $[200]$ & 2013 & 318 & Trastuzumab & Beta-blocker & Deaths, CHF & $\begin{array}{l}\text { Continuous use of beta-blocker is associated with lower incidence of HF in patients with } \\
\text { breast cancer and normal baseline ejection fraction }\end{array}$ \\
\hline
\end{tabular}

ACE-I: Angiotensin converting enzyme-Inhibitor; HF: Heart Failure; LVEF: Left Ventricular Ejection Fraction; LVSD: Left Ventricular Systolic Dysfunction

Table 4. Pooled analysis of echo/ECG diagnostic features and outcomes

\begin{tabular}{|c|c|c|c|c|}
\hline $\begin{array}{c}\text { Diagnostic Features/ } \\
\text { Outcomes }\end{array}$ & No. of studies & Events/ Total & Event Rate & P5\% CI \\
\hline Echo changes & $5[165-169,171]$ & $155 / 478$ & 0.328 & 0.029 \\
\hline ECG abnormalities & $3[148,163,169]$ & $94 / 185$ & 0.663 & 0.316 \\
\hline LV Hypertrophy & $3[165,169,170]$ & $34 / 231$ & 0.311 & 0.320 \\
\hline T-wave changes & $2[148,163]$ & $56 / 178$ & 0.440 & 0.830 \\
\hline ST changes & $2[148,163]$ & $33 / 178$ & 0.229 & 0.482 \\
\hline Tachycardia & $5[148,163-165,169]$ & $75 / 394$ & 0.274 & 0.084 \\
\hline Deaths & $5[148,164,166,167,171]$ & $24 / 228$ & 0.144 & 0.080 \\
\hline
\end{tabular}

Weighted Mean Difference and 95\% Cl: LVEF Changes

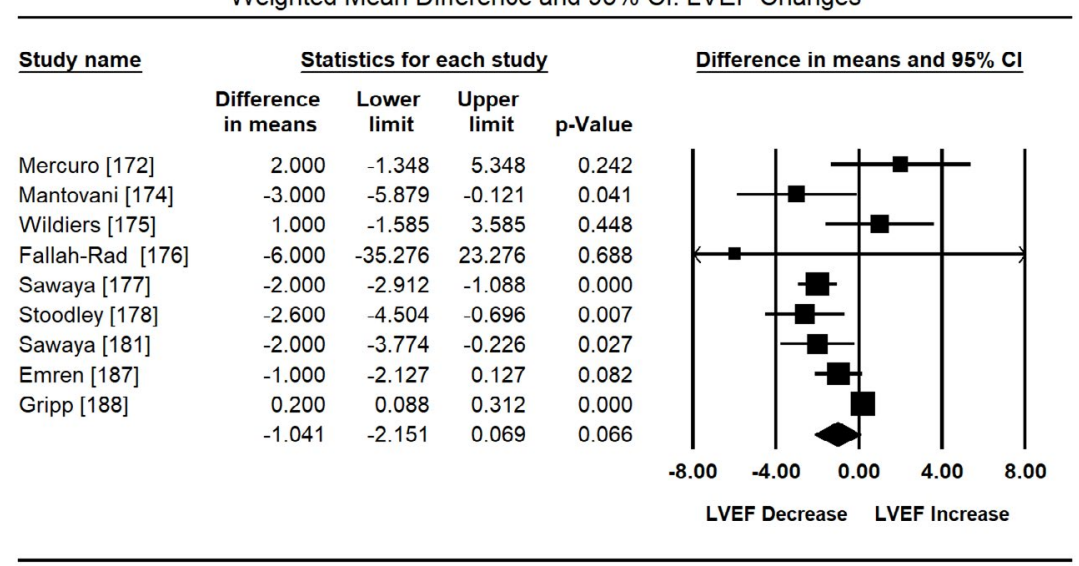

Test for Heterogeinity: $1^{\wedge} 2=82.64 \% ; p=0.000$

Figure 1. Forest plots for mean difference for LV ejection fraction 
Weighted Mean Difference and 95\% Cl: Global Longitudinal Strain

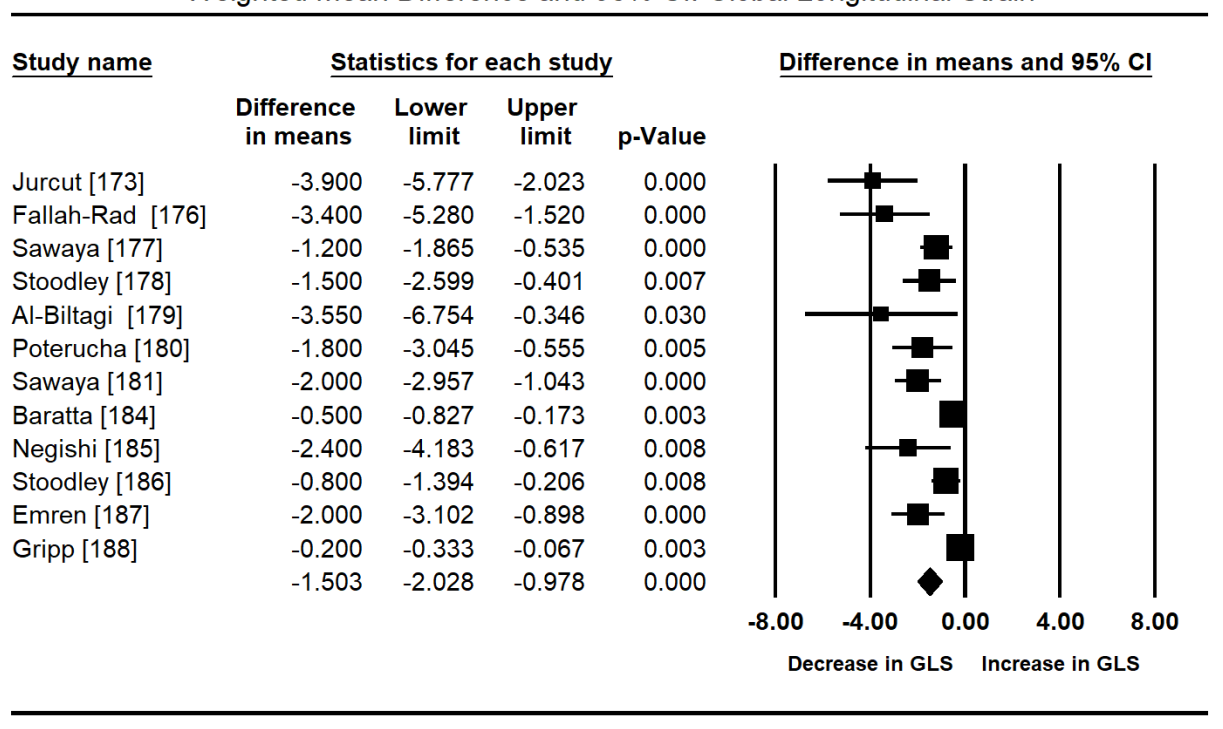

Test for Heterogeinity: $I^{\wedge} 2=85.44 \% ; p=0.000$

Figure 2. Forest plot for mean difference for global longitudinal strain

Weighted Mean Difference and 95\% Cl: Longitudinal Strain Rate

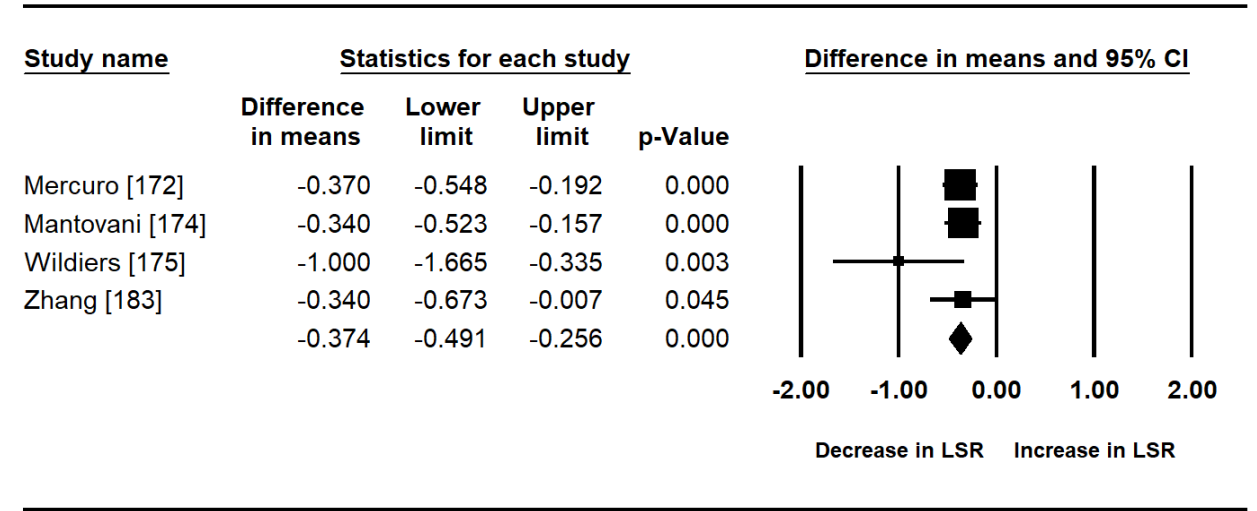

Test for Heterogeinity: $\left.\right|^{\wedge} 2=16.14 \% ; p=0.311$

Figure 3. Forest plot for mean difference for longitudinal strain rate

Weighted Mean Difference and $95 \% \mathrm{Cl}$ : RS Changes

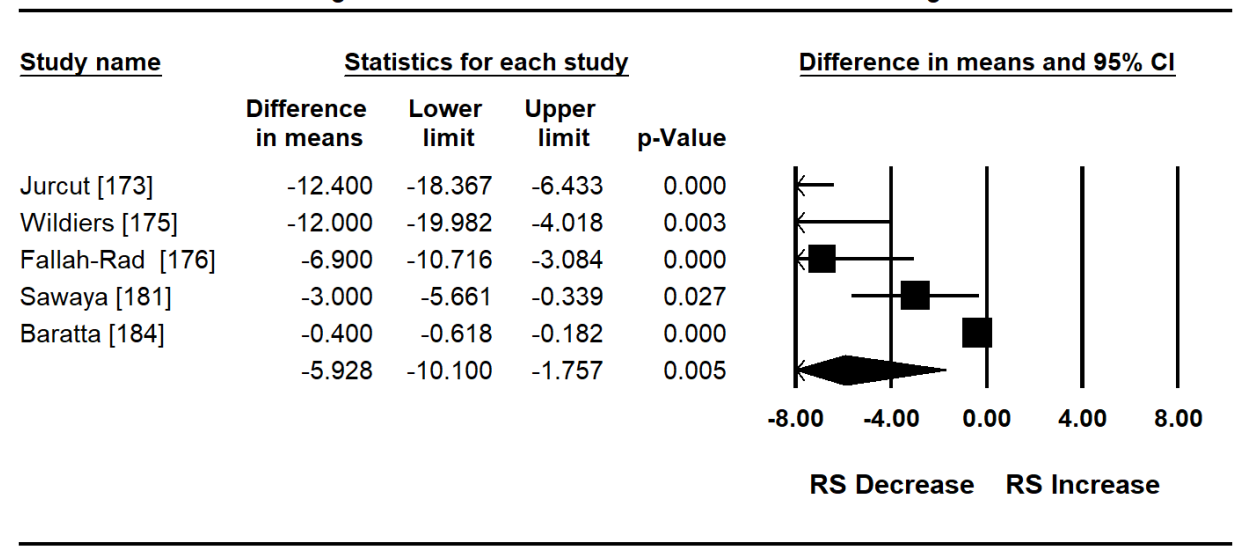

Test for Heterogeinity: $\left.\right|^{\wedge} \mathbf{2}=89.51 \% ; p=0.000$

Figure 4. Forest plot for mean difference for radial strain 
95\% CI; 0.105 to $1.125 ; \mathrm{p}=0.077$ ) (Figure 5). Two studies [190,191] evaluating dexrazoxane revealed a significant reduction $(84 \%)$ in the risk of cardiotoxicity when used in combination with anthracyclines (OR: 0.157; 95\% CI: 0.056 to $0.438 ; \mathrm{p}=0.000$ ). The use of cardioprotective adjuvants with anti-cancer drugs in four trials [190,195,198,200] showed a significant $78 \%$ decrease in the risk of CHF (OR: 0.222; 95\% CI: 0.118 to $0.417 ; p=0.000$ ) (Figure 6). Finally, pooled data from six studies $[189,192,194,196,198,200]$ showed a positive trend towards reduced risk of death (OR: 0.603 ; 95\% CI: 0.342 to $1.063 ; \mathrm{p}=0.080$ ) (Figure 7).

\section{Discussion}

Numerous medically prescribed drugs with cardiotoxic effects can cause CM although the bulk of the current evidence is centred on anticancer drugs. The disproportionate focus on anti-cancer drugs may be attributable to the large population of cancer survivors and increasing cases of CM and HF as long-term outcomes in these patients. In fact, as early as in the 1990 , nearly $70 \%$ of paediatric patients diagnosed with malignancy became long-term survivors and may reasonably be described are cured [201]. However, the success in clinical management

Odds Ratio and 95\% Cl: Cardioprotection

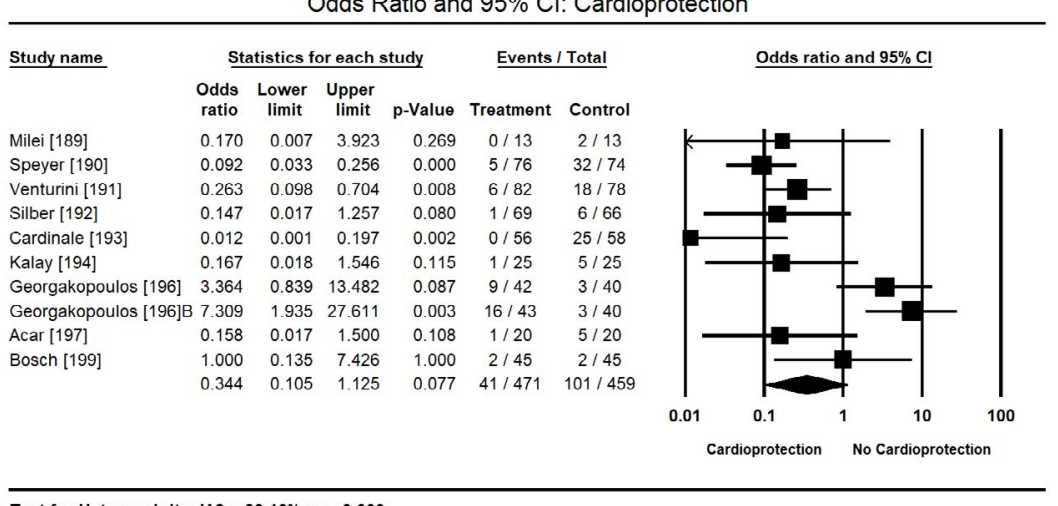

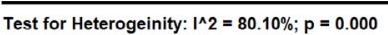

Figure 5. Forest plot for odds ratio for cardiotoxicity

Odds Ration and 95\% Cl: Congestive Heart Failure

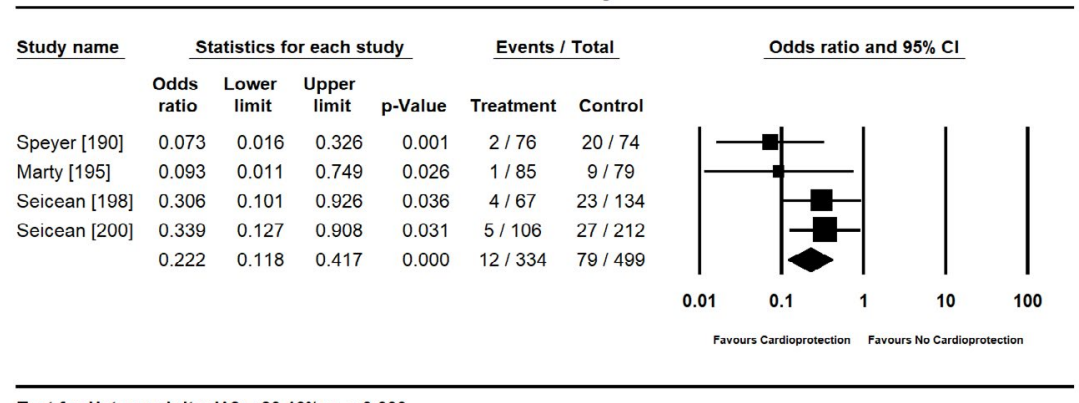

Test for Heterogeinity: $1^{\wedge} \mathbf{2}=\mathbf{8 0 . 1 0 \% ; p}=0.000$

Figure 6. Forest plot for odds ratio for congestive heart failure

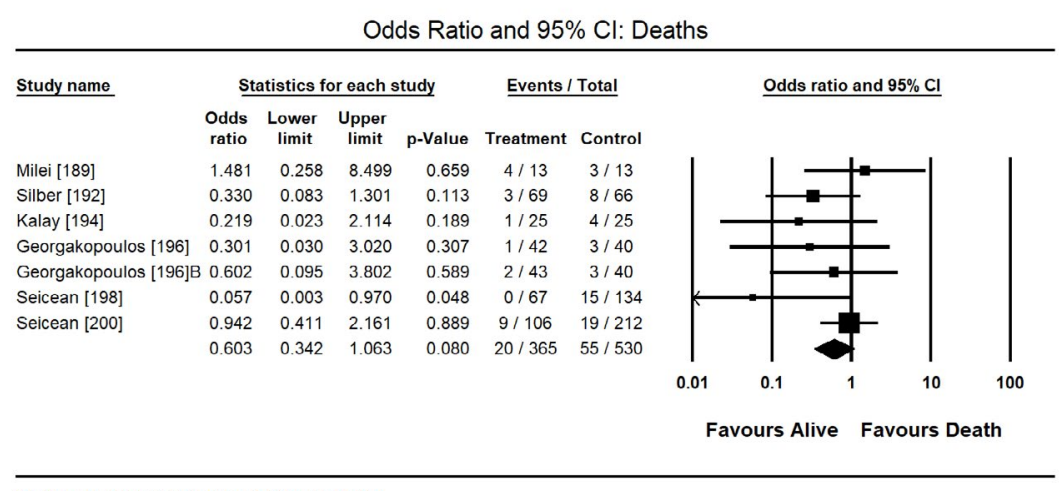

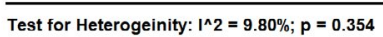

Figure 7. Forest plot for odds ratio for deaths 
of cancer has been achieved at a significant cost in terms of adverse side effects associated with the intense treatment needed to achieve this therapeutic efficacy. Consequently, there is an estimated 250,000 long-term survivors of paediatric cancer with about a half exposed to anthracycline therapy with half of those receiving anthracycline drugs developing cardiac problems [201,202]. Similarly, the present metaanalysis, which included 3,069 across 39 studies, had 35 out of 39 studies (90\%) evaluating anti-cancer drugs, with the remaining evaluating four antipsychotic or antiretroviral drugs. The evidence of cardiotoxicity and/or CM associated with antipsychotic and antiretroviral drugs have been described mostly in case reports and such evidence cannot allow pooled analysis.

In the present findings, the evidence of ECG abnormalities and echocardiographic ventricular abnormalities was observed in $66.3 \%$ and $32.8 \%$ respectively of patients on antipsychotic, antiretroviral or anticancer therapy. In particular, LV hypertrophy, ST-T changes, tachycardia and death were common presentations in these patients. Although echocardiographic changes in LV function are common, LVEF changes are non-specific and non-significant especially during the subclinical phase of drug-induced CM $(p=0.066)$. Myocardial (deformation) strain imaging using GLS, LSR and SR by STE or TDI is a feasible and promising tool to detect subtle pre-clinical changes in LV systolic function before conventional indices such as LVEF or suggest increased likelihood that depressed LV will develop with continued therapy. Treatment using cardioprotective adjuvant (dexrazoxane or HF medication) is a promising strategy to prevent cardiotoxicity and death. In particular, dexrazoxane used in combination with anti-cancer drugs offers $84 \%$ protection against cardiotoxicity. Cardioprotective drugs also prevents the risk of HF by $78 \%$. Although data on the effect of dose modulation and/or treatment cessation on cardiotoxicity was insufficient for a pooled analysis, there are suggestions from individual studies that they may present a promising intervention to prevent or limit cardiotoxicity. However, additional clinical trials are warranted to confirm the value of dose modulation especially for anthracycline therapy, in which cardiotoxicity is dose-dependent.

\section{Clinical Investigation: electrocardiography}

The diagnosis of cardiotoxicity and $\mathrm{CM}$ in patients receiving medically prescribed drugs with cardiotoxic effects remains challenging, particularly during the sub-clinical phase of the disease. ECG is considered a simple and inexpensive tool used to monitor and manage cardiovascular diseases. In the present meta-analysis, ECG abnormalities occurred in about $66 \%$ of patients receiving anti-cancer drugs but the abnormalities are non-specific to drug-induced CM or predictive for the development of $\mathrm{CM}$ in future. Consistent with the present finding, a previous clinical trial evaluating serum biomarkers and ECG/echocardiography on cancer patients receiving high dose cyclophosphamide reported ECG abnormalities are common in CM associated with cyclophosphamide [203]. In the study, acute manifestation of CM commonly present with sinus tachycardia, ECG abnormalities mostly ST-T wave changes, reduced QRS voltage or QRS prolongation although the ECG changes are not sensitive specific for diagnosing or monitoring drug-induced cardiotoxicity [203]. However, in cancer patients receiving chemotherapy with presentations of chest pain, palpitations or dyspnoea, ECG abnormalities suggest a contributing or concomitant condition in addition to CM such as acute coronary syndrome, pericarditis, arrhythmias, or the presence of pericardial effusion [204]. Further, infiltrative disease such as cardiac amyloid has an association between cardiac involvement and low ECG voltage [204].
Conventional echocardiography: The present findings also show echocardiography evidence of LV dysfunction is common in druginduced CM, which occurred in $32.8 \%$ of patients exposed to cytotoxic drugs mostly anti-cancer drugs. Consistent with these findings, Morandi et al. [203] reported echocardiographic changes in $25 \%$ of patients on chemotherapy. The role of echocardiography in the diagnosis of drug-induced CM has been supported in literature. It is a frequently used non-invasive technique for assessing and monitoring cardiac function in cancer patients due to its convenience, cost-effectiveness, non-ionizing radiation and comprehensive cardiac evaluation [204]. The most widely assessed parameter for LV systolic function is LVEF $[76,77]$. Even expert consensus for multimodality imaging evaluation of adult patients during and after cancer therapy by the American Society of Echocardiography and the European Association of Cardiovascular Imaging is based on LVEF, defined as LVEF decrease $\geq 5 \%$ to $<55 \%$ for symptomatic patients and LVEF decrease $\geq 10 \%$ to $<55 \%$ for asymptomatic patients [205]. This reduction in LVEF should be confirmed by repeat echocardiography assessment performed 2 to 3 weeks after baseline diagnostic study revealing the initial decreased in LVEF. Furthermore, the guidelines categorize cardiotoxicity defined by LVEF cut-off values into three categories as follows:

a) Reversible cardiotoxicity: a reduction of LVEF by $<5 \%$;

b) Partially reversible cardiotoxicity: LVEF improved by $\geq 10 \%$ from nadir but remaining $>5 \%$ below baseline; and

c) Irreversible cardiotoxicity: LVEF improved by $<10 \%$ from nadir and remaining $>5 \%$ below baseline.

Despite the value of echocardiography in diagnosing cardiotoxicity, the modality has notable limitations. In the present findings, changes in LVEF in cancer patients with normal LV systolic function receiving chemotherapy were non-significant $(p=0.066)$, suggesting its inability to detect subtle changes in myocardial structure. Similarly, while monitoring changes in systolic function is extensively used on clinical practice, it has not achieved the desired goal of detecting subclinical cardiac injury with suggestions that the addition of indices for diastolic function may improve diagnosis of subtle changes in cardiac structure and function [206]. In an early study comparing cardiac biopsy and LVEF, Ewer et al. [207] found poor correlation between changes in biopsy and LVEF. Some patients had normal LVEF values despite structural changes of Adriamycin cardiotoxicity, demonstrating that LVEF may underestimate the extent of cardiac dysfunction. The underestimation has been attributed to cardiac compensatory reserve, which is able to preserve LVEF despite loss of myocyte function and it is not until the reserve is depleted that a decrease in LVEF may be observed. In addition, bi-plane assessment of LVEF has important limitations including geometric assumptions, foreshortening and the lack of consideration of all LV walls [208].

Speckle tracking echocardiography: Newer echocardiography modalities such as myocardial strain imaging have been proposed as promising tools to detect subclinical changes in LV function prior to discernible LVEF changes. Speckle tracking echocardiography, which is a pre-load independent measure of myocardial deformation, is a recent addition to echocardiographic modalities for detecting early changes in patients with drug-induced CM [206]. In the present analysis, myocardial strain imaging by STE or TDI reveals significant deterioration by $-1.5 \%$ in GLS, $-1.37 \%$ in LSR and $-5.92 \%$ in RS in patients receiving anti-cancer drugs. Subclinical changes in myocardial strain imaging have been shown to precede systolic dysfunction $[209,210]$. In a systematic review of the role of echocardiography 
in detecting cardiotoxicity in breast cancer patients, Tadic and Cuspidi [208] myocardial strain imaging could detect early signs of chemotherapy-induced CM even one week after the introduction of anthracycline therapy, and subsequent deterioration in LV mechanics 3,6, and 12 months after chemotherapy. These findings suggest that LV strain is an important marker for LV dysfunction useful for both detection of cardiotoxicity and monitoring of potential improvement of LV function after chemotherapy [208].

Whereas the present analysis combined the findings of myocardial strain imaging assessed by STE and TDI, important limitations regarding TDI have been described. These limitations include relatively low reproducibility, assessment of myocardial deformation only in one dimension and the assessment of only regional strain [208]. STE overcomes these limitations by offering a comprehensive assessment of myocardial function. STE provides accurate and reproducible longitudinal and circumferential strain, which is clinically relevant since LV longitudinal strain deteriorates earlier than any discernible changes in LV pump function (LVEF). Longitudinal strain is also an early predictor of cardiotoxicity and an independent predictor of cardiac recovery in chemotherapy-induced $\mathrm{CM}$ in breast cancer patients on trastuzumab and anthracycline therapy [211,212]. A recent study by Tan et al. [213] on trends of LVEF and myocardial deformation in a cohort of women with breast cancer reported LV mechanical dysfunction persists $>2$ year after the cessation of anthracycline and trastumuzab treatment with no significant recovery after termination of trastuzumab therapy suggesting long-term underlying cardiac injury and remodelling. Khouri et al. [214] found in contract to the traditional 2D parameters (LVEF), 3D LVEF, 2D GLS and exercisestress echocardiography are able to detect cardiac dysfunction in $\mathrm{BC}$ patients treated with doxorubicin-containing adjuvant therapy.

Besides myocardial strain, Motoki et al. [215] demonstrates that twist, torsion and untwisting rate are impaired one month after anthracycline therapy, suggesting they are a more sensitive indicator of chemotherapy induced CM than longitudinal strain. However, the ability of twist and torsion to predict subsequent cardiotoxicity needs to be evaluated in larger multi-centre and longitudinal clinical trials. Finally, although the present analysis did not evaluate the role of cardiac biomarkers in clinical evaluation, assessment and monitoring of cardiotoxicity during chemotherapy, troponin levels is emerging as a promising tool to identify patients at risk of cardiotoxicity $[78,79]$. Although the value and duration of troponin elevation correlates with the extent of LV dysfunction, the optimal cut-off points for troponin levels for diagnosis of cardiotoxicity remain not well defined in all population and would need to be individualized. However, cardiac troponin levels used together with myocardial stain measure appear to provide better prediction for the development of cardiotoxicity than other biomarkers and imaging alone $[78,177]$.

\section{Clinical management: cardioprotective adjuvants}

The present meta-analysis finds cardioprotective agents given in combination with anti-cancer drugs in cancer patients shows a positive trend towards reduced risk of cardiotoxicity (OR: 0.344), reduced CHF (OR: 0.222); and a trend towards reduced deaths (OR: 0.603). Dexrazoxane in combination with anti-cancer drugs reduced the risk of cardiotoxicity by $84 \%$ (OR: 0.157 ). Treatment effectiveness of dexrazoxane in preventing or delaying cardiotoxicity in patients receiving anti-cancer drugs has been demonstrated in previous studies as well as in expert consensus reports. A previous metaanalysis of six randomized trials enrolling 1013 cancer patients (both adult and paediatric) reported significantly decreased incidence of HF after treatment with dexrazoxane [216]. Cardioprotective effect of dexrazoxane has also been described in in children with high-risk acute lymphoblastic leukaemia receiving chronic doxorubicin therapy (10 doses of $30 \mathrm{mg} / \mathrm{m}^{2}$ ) [217,218]. Although dexrazoxane is the only approved drug by Food and Drug Administration (FDA) and European Medicines Agency (EMA), its use as a cardioprotective adjuvant is limited to women with metastatic breast cancer who have received cumulative doses of $300 \mathrm{mg} / \mathrm{m}^{2}$ doxorubicin [219,220]. The primary mechanism for cardioprotection was initially thought to be through iron chelation. However, with the recognition that other iron chelators do not produce a similar performance, its mechanism of protection is now thought to be through the interference with topoisomerase $2 \beta$, which conceals DNA double strand breaks [221].

Another strategy for protecting against cardiac dysfunction is the use of ACE-inhibitors including enalapril, zofenopril and lisinopril even before the development of cardiotoxicity. ACE-inhibitors are commonly used in patients who have developed signs of HF as afterload reducing agents. In addition to their effect as ACE inhibitors, these drugs may act as antioxidant and thus may contribute to prevention of cardiotoxicity [220]. In a recent preclinical study, Hiona et al. [222] demonstrate enalapril attenuate doxorubicin-induced cardiac dysfunction by preserving mitochondrial respiratory efficiency and reduction of doxorubicin-associated free radical generation. However, some important observations in the use of ACE-inhibition in patients receiving anticancer treatment have been described. In long-term doxorubicin-treated survivors of childhood cancer, the beneficial effect of ACE-I (enalapril) in improving LV structure and function appeared to disappear after six or ten years. ACE-I inhibitors also have adverse side effects and thus the choice of this drug as a cardioprotective adjuvant during anti-cancer treatment should be carefully evaluated [192].

Dose modulation/cessation: The present meta-analysis did not evaluate dose modulation or cessation as a strategy to prevent cardiotoxicity in cancer patients receiving chemotherapy due to lack of sufficient data. However, there were suggestions of improvement in cardiac function and reduction or elimination of cardiotoxicity. Ronaldson et al. [148] reported recovery of clozapine-induced myocarditis in all 36 patients following treatment following withdrawal of clozapine therapy. Recovery was indicated by normalization of heart rate to $<100$ beats per minutes in 29 cases, a fall in cardiac troponin level to normal in 25 cases and incomplete reduction in 3 cases. In 17 cases with echocardiography follow-up five days after clozapine withdrawal, normal cardiac function was observed in 12 cases, improvement in 4 cases and one case remained unchanged but had normalized heart rare and troponin levels. In schizophrenic patients on phenothiazines therapy, treatment withdrawal was associated with disappearance of ECG abnormalities (ST-T wave changes, PR and QT prolongation) in $34 \%$ of the patients [163]. In cases where treatment withdrawal may potential lead to worsening outcomes for cancer, primary prophylactic strategy against cardiotoxicity is via dose modulation. For anthracyclines, current guidelines recommend administering the drug via continuous infusion rather than bolus infusion or using less cardiotoxic derivatives such as Epirubicn or idarubicin [62,64].

Clinical implications: Drug-induced CM is a serious adverse effect of many cytotoxic drugs, which threaten to undermine longterm efficacy of culprit drugs. Early identification of cardiotoxicity is important to improve treatment efficacy and patient survival. However, early diagnosis of drug-induced CM remains a clinical challenge. The 
most widely assessed parameter for LV systolic function is LVEF [76,77] cannot detect subclinical changes while new imaging modalities such as STE are not widely available and require additional training. Using a combination of ECG, cardiac biomarkers and LVEF may improve early diagnosis of drug-induced CM in centres without STE equipment or the necessary expertise. The ability of STE (or mechanical changes) to predict subsequent cardiotoxicity needs to be evaluated in larger multi-centre trials. There is also a need to evaluate whether strain measurement are required at a single point in time or serially as well as long-term effect of strain changes that appear during treatment and the prognostic significance of these changes.

\section{Conclusion}

Cardiomyopathy (CM) resulting from chronic exposure to medically prescribed cardiotoxic drugs reduces their treatment efficacy. The list of prescription drugs with cardiotoxicity is long but anti-cancer, antiretroviral, antipsychotic and chloroquine are among the major causes. With many of these drugs improving longevity in the targeted patient populations, their cardiotoxic effects continue to feature more prominently in the long-term outcomes. Pathophysiological mechanisms vary based on the inciting drug agent, which includes direct cardiotoxic effect, mitochondrial toxicity, neurohormonal activation and reactive oxygen species. Side effects also vary in presentation and severity from subclinical disease to cardiac dysfunction, heart failure and death. Diagnosis and clinical management vary depending on the culprit drug. Routine clinical monitoring for cardiac dysfunction and cardiotoxicity should be considered for early recognition of the disease. As drug-induced CM is potentially reversible, immediate withdrawal of the culprit drug or dose modulation is a key clinical management strategy associated with a reduction in cardiotoxicity and a reversal of myocardial damage. Alternatively, appropriate selection of alternative derivatives having lower cardiotoxic levels or the concomitant use of cardioprotective adjuvant is a promising strategy to reduce the risk of CM. Finally, since drug-induced CM is an unfortunate side effect, prescribers should be aware of potential cardiotoxicity of drugs, perform routine monitoring, and if cardiotoxicity is identified, the withdrawal of therapy or the use of alternative drugs with less cardiotoxicity should be considered based on therapeutic benefits and extent of myocardial damage.

\section{References}

1. Maron BJ, Towbin JA, Thiene G, Antzelevitch C, Corrado D, et al. (2006) Contemporary definitions and classification of the cardiomyopathies: an American Heart Association scientific statement from the council on clinical cardiology, heart failure and transplantation committee; quality of care and outcomes research and functional genomics and translational biology interdisciplinary working groups; and council on epidemiology and prevention. Circulation 113: 1807-1816. [Crossref]

2. Elliott P, Andersson B, Arbustini E, Bilinska Z, Cecchi F, et al. (2008) Classification of the cardiomyopathies: a position statement from the European Society of Cardiology working group on myocardial and pericardial diseases. Eur Heart J 29: 270-276. [Crossref]

3. Bozkurt B, Colvin M, Cook J, Cooper LT, Deswal A, et al. (2016) Current diagnostic and treatment strategies for specific dilated cardiomyopathies: a scientific statement from the American Heart Association. Circulation 134: e579-e646. [Crossref]

4. Gupta A, Mandala A, Wee Y (2017) Drug-Induced Cardiomyopathy: An Institutional Experience. Heart, Lung and Circulation 26: S132-S133.

5. Wu AH (2008) Cardiotoxic drugs: clinical monitoring and decision-making. Heart 94: 1503-1509. [Crossref]

6. Figueredo VM (2011) Chemical cardiomyopathies: the negative effects of medications and non-prescribed drugs on the heart. Am J Med 124: 480-488. [Crossref]
7. Lipshultz SE, Lipsitz SR, Mone SM, Goorin AM, Sallan SE, et al. (1995) Female sex and drug dose as risk factors for late cardiotoxic effects of dox-Female sex and drug dose as risk factors for late cardiotoxic effects of doxorubicin therapy for childhood cancer. N Engl J Med 332: 1738-1743. [Crossref]

8. Steinherz LJ, Steinherz PG, Tan CT, Heller G, Murphy ML (1991) Cardiac toxicity 4 to 20 years after completing anthracycline therapy. Jama 266: 1672-1677. [Crossref]

9. Zucchi R, Danesi R (2003) Cardiac toxicity of antineoplastic anthracyclines. Curr Med Chem Anticancer Agents 3: 151-171. [Crossref]

10. Takemura G, Fujiwara H (2007) Doxorubicin-induced cardiomyopathy: from the cardiotoxic mechanisms to management. Prog Cardiovasc Dis 49: 330-352. [Crossref]

11. Swain SM, Whaley FS, Ewer MS (2003) Congestive heart failure in patients treated with doxorubicin: a retrospective analysis of three trials. Cancer 97: 2869-2879. [Crossref]

12. Jones LW, Haykowsky MJ, Swartz JJ, Douglas PS, Mackey JR (2007) Early breast cancer therapy and cardiovascular injury. J Am Coll Cardiol 50: 1435-1441. [Crossref]

13. Lipshultz SE, Alvarez JA, Scully RE (2008) Anthracycline associated cardiotoxicity in survivors of childhood cancer. Heart 94: 525-533. [Crossref]

14. Dong J, Chen H (2018) Cardiotoxicity of anticancer therapeutics. Front Cardiovasc Med 5: 9. [Crossref]

15. Dempsey KS (2011) Chemotherapy-induced cardiotoxicity in women. Heart Fail Clin 7: 427-435. [Crossref]

16. Hortobagyi GN (2005) Trastuzumab in the treatment of breast cancer. $N$ Engl J Med 353: 1734-1736. [Crossref]

17. Bartsch R, Wenzel C, Steger GG (2007) Trastuzumab in the management of early and advanced stage breast cancer. Biologics 1: 19-31. [Crossref]

18. Jain D, Russell RR, Schwartz RG, Panjrath GS, Aronow W (2017) Cardiac complications of cancer therapy: pathophysiology, identification, prevention, treatment, and future directions. Curr Cardiol Rep 19: 36. [Crossref]

19. Pun SC, Neilan TG (2016) Cardiovascular side effects of small molecule therapies for cancer. Eur Heart J 37: 2742-2745. [Crossref]

20. Gianni L, Dafni U, Gelber RD, Azambuja E, Muehlbauer S, et al. (2011) Treatment with trastuzumab for 1 year after adjuvant chemotherapy in patients with HER2positive early breast cancer: a 4-year follow-up of a randomised controlled trial. Lancet Oncol 12: 236-244. [Crossref]

21. Domercant J, Polin N, Jahangir E (2016) Cardio-oncology: a focused review of anthracycline-, human epidermal growth factor receptor 2 inhibitor-, and radiationinduced cardiotoxicity and management. Ochsner $J$ 16: 250-256. [Crossref]

22. Slamon DJ, Leyland-Jones B, Shak S, Fuchs H, Paton V, et al. (2001) Use of chemotherapy plus a monoclonal antibody against HER2 for metastatic breast cancer that overexpresses HER2. N Engl J Med 344: 783-792. [Crossref]

23. Russell SD, Blackwell KL, Lawrence J, Pippen Jr JE, Roe MT, et al. (2010) Independent adjudication of symptomatic heart failure with the use of doxorubicin and cyclophosphamide followed by trastuzumab adjuvant therapy: a combined review of cardiac data from the National Surgical Adjuvant breast and Bowel Project B-31 and the North Central Cancer Treatment Group N9831 clinical trials. J Clin Oncol 28 : 3416-3421. [Crossref]

24. Bowles EJ, Wellman R, Feigelson HS, Onitilo AA, Freedman AN, et al. (2012) Risk of heart failure in breast cancer patients after anthracycline and trastuzumab treatment: a retrospective cohort study. J Natl Cancer Inst 104: 1293-1305. [Crossref]

25. Ewer SM, Ewer MS (2008) Cardiotoxicity profile of trastuzumab. Drug Saf 31: 459467. [Crossref]

26. Suter TM, Procter M, Van Veldhuisen DJ, Muscholl M, Bergh J, et al. (2007) Trastuzumab-associated cardiac adverse effects in the herceptin adjuvant trial. $J$ Clin Oncol 25: 3859-3865. [Crossref]

27. Halyard MY, Pisansky TM, Dueck AC, Suman V, Pierce L, et al. (2009) Radiotherapy and adjuvant trastuzumab in operable breast cancer: tolerability and adverse event data from the NCCTG Phase III Trial N9831. J Clin Oncol 27: 2638-2644. [Crossref]

28. Perez EA, Suman VJ, Davidson NE, Sledge GW, Kaufman PA, et al. (2008) Cardiac safety analysis of doxorubicin and cyclophosphamide followed by paclitaxel with or without trastuzumab in the North Central Cancer Treatment Group N9831 adjuvant breast cancer trial. J Clin Oncol 26: 1231-1238. [Crossref] 
29. Romond EH, Jeong JH, Rastogi P, Swain SM, Geyer Jr CE, et al. (2012) Sevenyear follow-up assessment of cardiac function in NSABP B-31, a randomized trial comparing doxorubicin and cyclophosphamide followed by paclitaxel (ACP) with ACP plus trastuzumab as adjuvant therapy for patients with node-positive, human epiderma growth factor receptor 2-positive breast cancer. J Clin Oncol 30: 3792-3799. [Crossref]

30. Cheungpasitporn W, Kopecky SL, Specks U, Bharucha K, Fervenza FC (2017) Nonischemic cardiomyopathy after rituximab treatment for membranous nephropathy. $J$ Renal Inj Prev 6: 18-25. [Crossref]

31. Plosker GL, Figgitt DP (2003) Rituximab: a review of its use in non-Hodgkin's lymphoma and chronic lymphocytic leukaemia. Drugs 63: 803-843. [Crossref]

32. Garypidou V, Perifanis V, Tziomalos K, Theodoridou S (2004) Cardiac toxicity during rituximab administration. Leuk Lymphoma 45: 203-204. [Crossref]

33. Millward PM, Bandarenko N, Chang PP, Stagg KF, Afenyi-Annan A, et al. (2005) Cardiogenic shock complicates successful treatment of refractory thrombotic thrombocytopenia purpura with rituximab. Transfusion 45: 1481-1486. [Crossref]

34. Gershwin ME, Goetzl EJ, Steinberg AD (1974) Cyclophosphamide: use in practice. Ann Intern Med 80: 531-540. [Crossref]

35. Dhesi S, Chu MP, Blevins G, Paterson I, Larratt L, et al. (2013) Cyclophosphamideinduced cardiomyopathy: a case report, review, and recommendations for management J Investig Med High Impact Case Rep 1: 2324709613480346. [Crossref]

36. Goldberg MA, Antin JH, Guinan EC, Rappeport JM (1986) Cyclophosphamide cardiotoxicity: an analysis of dosing as a risk factor. Blood 68: 1114-1118. [Crossref]

37. Baba J, Watanabe S, Saida Y, Tanaka T, Miyabayashi T, Koshio J, et al. (2012) Depletion of radio-resistant regulatory $\mathrm{T}$ cells enhances antitumor immunity during recovery from lymphopenia. Blood 120: 2417-2427. [Crossref]

38. Winkelstein A(1973) Mechanisms of immunosuppression: effects of cyclophosphamide on cellular immunity. Blood 41: 273-284. [Crossref]

39. Makinodan T, Santos GW, Quinn RP (1970) Immunosuppressive drugs. Pharmacol Rev 22: 189-247. [Crossref]

40. Shanholtz C (2001) Acute life-threatening toxicity of cancer treatment. Crit Care Clin 17: 483-502. [Crossref]

41. Appelbaum F, Strauchen J, Graw JR R, Savage D, Kent K, et al. (1976) Acute lethal carditis caused by high-dose combination chemotherapy: a unique clinical and pathological entity. Lancet 307: 58-62. [Crossref]

42. Katayama M, Imai Y, Hashimoto H, Kurata M, Nagai K, et al. (2009) Fulminant fatal cardiotoxicity following cyclophosphamide therapy. J Cardiol 54: 330-334. [Crossref]

43. Kamezaki K, Fukuda T, Makino S, Harada M (2005) Cyclophosphamide-induced cardiomyopathy in a patient with seminoma and a history of mediastinal irradiation. Intern Med 44: 120-123. [Crossref]

44. Birchall IW, Lalani Z, Venner P, Hugh J (2000) Fatal haemorrhagic myocarditis secondary to cyclophosphamide therapy. Br J Radiol 73: 1112-1114. [Crossref]

45. Nieto Y, Cagnoni PJ, Bearman SI, Shpall EJ, Matthes S, et al. (2000) Cardiac toxicity following high-dose cyclophosphamide, cisplatin, and BCNU (STAMP-I) for breast cancer. Biol Blood Marrow Transplant 6: 198-203. [Crossref]

46. Brockstein BE, Smiley C, Al-Sadir J, Williams SF. Cardiac and pulmonary toxicity in patients undergoing high-dose chemotherapy for lymphoma and breast cancer: prognostic factors. Bone Marrow Transplant 25: 885-894. [Crossref]

47. Hertenstein B, Stefanic M, Schmeiser T, Scholz M, Göller V, et al. (1994) Cardiac toxicity of bone marrow transplantation: predictive value of cardiologic evaluation before transplant. J Clin Oncol 12: 998-1004. [Crossref]

48. Santos GW, Sensenbrenner LL, Burke PJ, Colvin M, Owens JA (1971) Marrow transplanation in man following cyclophosphamide. In Transplantation proceedings 3 : 400-404. [Crossref]

49. Storb R, Buckner CD, Dillingham LA, Thomas ED (1970) Cyclophosphamide regimens in rhesus monkeys with and without marrow infusion. Cancer Res 30: 2195 2203. [Crossref]

50. Bearman SI, Petersen FB, Schor RA, Denney JD, Fisher LD (1990) Radionuclide ejection fractions in the evaluation of patients being considered for bone marrow transplantation: risk for cardiac toxicity. Bone Marrow Transplantat 5: 173-177. [Crossref]

51. Goodman VL, Rock EP, Dagher R, Ramchandani RP, Abraham S, et al. (2007) Approval summary: sunitinib for the treatment of imatinib refractory or intoleran gastrointestinal stromal tumours and advanced renal cell carcinoma. Clin Cancer Res 13: 1367-1373. [Crossref]
52. Adams VR, Leggas M (2007) Sunitinib malate for the treatment of metastatic renal cell carcinoma and gastrointestinal stromal tumors. Clin Ther 29: 1338-1353. [Crossref]

53. Chu TF, Rupnick MA, Kerkela R, Dallabrida SM, Zurakowski D, Nguyen L, Woulfe K Pravda E, Cassiola F, Desai J, George S. Cardiotoxicity associated with tyrosine kinase inhibitor sunitinib. Lancet 370: 2011-2019. [Crossref]

54. Distler JH, Distler O (2007) Cardiotoxicity of imatinib mesylate: an extremely rare phenomenon or a major side effect?. Ann Rheum Dis 66: 836. [Crossref]

55. Druker BJ, Tamura S, Buchdunger E, Ohno S, Segal GM, et al. (1996) Effects of a selective inhibitor of the Abl tyrosine kinase on the growth of Bcr-Abl positive cells Nat Med 2: 561-566. [Crossref]

56. Demetri GD, Von Mehren M, Blanke CD, Van den Abbeele AD, Eisenberg B, et al (2002) Efficacy and safety of imatinib mesylate in advanced gastrointestinal stromal tumors. N Engl J Med 347: 472-480. [Crossref]

57. Druker BJ, Talpaz M, Resta DJ, Peng B, Buchdunger E, et al. (2001) Efficacy and safety of a specific inhibitor of the BCR-ABL tyrosine kinase in chronic myeloid leukemia. N Engl J Med 344: 1031-1037. [Crossref]

58. Ghofrani HA, Seeger W, Grimminger F (2005) Imatinib for the treatment of pulmonary arterial hypertension. $N$ Engl J Med 353: 1412-1413. [Crossref]

59. Paniagua RT, Sharpe O, Ho PP, Chan SM, Chang A, et al. (2006) Selective tyrosine kinase inhibition by imatinib mesylate for the treatment of autoimmune arthritis J Clin Invest 116: 2633-2642. [Crossref]

60. Distler JH, Jüngel A, Huber LC, Schulze-Horsel U, Zwerina J, et al. (2007) Imatinib mesylate reduces production of extracellular matrix and prevents development of experimental dermal fibrosis. Arthritis Rheum 56: 311-322. [Crossref]

61. Savi M, Frati C, Cavalli S, Graiani G, Galati S, et al. (2018) Imatinib mesylate-induced cardiomyopathy involves resident cardiac progenitors. Pharmacol Res 127: 15-25. [Crossref]

62. Klimas J (2012) Drug-induced cardiomyopathies. In Cardiomyopathies - From Basic Research to Clinical Management 2012 Feb 15. IntechOpen

63. Zuppinger C, Timolati F, Suter TM (2007) Pathophysiology and diagnosis of cancer drug induced cardiomyopathy. Cardiovasc Toxicol 7: 61-66. [Crossref]

64. Shakir DK, Rasul KI (2009) Chemotherapy induced cardiomyopathy: pathogenesis, monitoring and management. J Clin Med Res 1: 8-12. [Crossref]

65. Gewirtz D (1999) A critical evaluation of the mechanisms of action proposed for the antitumor effects of the anthracycline antibiotics adriamycin and daunorubicin. Biochem Pharmacol 57: 727-741. [Crossref]

66. Horenstein MS, Vander Heide RS, L'Ecuyer TJ (2000) Molecular basis of anthracyclineinduced cardiotoxicity and its prevention. Mol Genet Metab 71: 436-444. [Crossref]

67. Hershko C, Link G, Tzahor M, Pinson A (1993) The role of iron and iron chelators in anthracycline cardiotoxicity. Leuk Lymphoma, 11: 207-214. [Crossref]

68. Link G, Tiros R, Pinson A, Hershko C (1996) Role of iron in the potentiation of anthracycline cardiotoxicity: identification of heart cell mitochondria as a major site of iron-anthracycline interaction. J Lab Clin Med 127: 272-278. [Crossref]

69. Doroshow JH (1983) Effect of anthracycline antibiotics on oxygen radical formation in rat heart. Cancer Res 43: 460-472. [Crossref]

70. Ehrke MJ, Maccubbin D, Ryoyama K, Cohen SA, Mihich E (1986) Correlation between adriamycin-induced augmentation of interleukin 2 production and of cellmediated cytotoxicity in mice. Cancer Res 46: 54-60. [Crossref]

71. Zhang S, Liu X, Bawa-Khalfe T, Lu LS, Lyu YL, et al. (2012) Identification of the molecular basis of doxorubicin-induced cardiotoxicity. Nat Med 18: 1639-1642. [Crossref]

72. Wouters KA, Kremer L, Miller TL, Herman EH, Lipshultz SE (2005) Protecting against anthracycline-induced myocardial damage: a review of the most promising strategies. Br J Haematol 131: 561-578. [Crossref]

73. Kalyanaraman BJ, Joseph J, Kalivendi S, Wang S, Konorev E, et al. (2002) Doxorubicininduced apoptosis: implications in cardiotoxicity. In Oxygen/Nitrogen Radicals: Cell Injury and Disease, (pp. 119-124). Springer US.

74. Crone SA, Zhao YY, Fan L, Gu Y, Minamisawa S, et al. (2002) ErbB2 is essential in the prevention of dilated cardiomyopathy. Nat Med 8: 459-465. [Crossref]

75. Piper SE, McDonagh TA (2015) Chemotherapy-related cardiomyopathy Eur Cardiol 10, 19-24. [Crossref] 
76. Curigliano G, Cardinale D, Suter T, Plataniotis G, De Azambuja E, et al. (2012) ESMO Guidelines Working Group. Cardiovascular toxicity induced by chemotherapy, targeted agents and radiotherapy: ESMO Clinical Practice Guidelines. Ann Oncol 23: vii155-66. [Crossref]

77. Plana JC, Galderisi M, Barac A, Ewer MS, Ky B, et al. (2014) Expert consensus for multimodality imaging evaluation of adult patients during and after cancer therapy: a report from the American Society of Echocardiography and the European Association of Cardiovascular Imaging. J Am Soc Echocardiogr 15: 1063-1093. [Crossref]

78. Cardinale D, Sandri MT, Colombo A, Colombo N, Boeri M, et al. (2004) Prognostic value of troponin I in cardiac risk stratification of cancer patients undergoing high-dose chemotherapy. Circulation 109: 2749-2754. [Crossref]

79. Cardinale D, Sandri MT (2010) Role of biomarkers in chemotherapy-induced cardiotoxicity. Prog Cardiovasc Dis 53: 121-129. [Crossref]

80. Cheitlin MD, Armstrong WF, Aurigemma GP, Beller GA, Bierman FZ, et al. (2003) ACC/AHA/ASE 2003 guideline update for the clinical application of echocardiography: summary article: a report of the American College of Cardiology/American Heart Association Task Force on Practice Guidelines. Circulation 108: 1146-1162. [Crossref]

81. Hensley ML, Hagerty KL, Kewalramani T, Green DM, Meropol NJ, et al. (2009) American Society of Clinical Oncology 2008 clinical practice guideline update: use of chemotherapy and radiation therapy protectants. J Clin Oncol 27: 127-145. [Crossref]

82. Steinherz LJ, Brochstein JA, Robins J (1986) Cardiac involvement in congenital acquired immunodeficiency syndrome. Am J Dis Child 140: 1241-1244. [Crossref]

83. Joshi VV, Gadol C, Connor E, Oleske JM, Mendelson J, et al. (1988) Dilated cardiomyopathy in children with acquired immunodeficiency syndrome: A pathologic study of five cases. Hum Pathol 19: 69-73. [Crossref]

84. Johann-Liang R, Cervia JS, Noel GJ (1997) Characteristics of human immunodeficiency virus-infected children at the time of death: an experience in the 1990s. Pediatr Infect Dis J 16: 1145-1150. [Crossref]

85. Brady MT, Oleske JM, Williams PL, Elgie C, Mofenson LM, et al. (2010) Pediatric AIDS Clinical Trials Group219/219C Team. Declines in mortality rates and changes in causes of death in HIV-1-infected children during the HAART era. $J$ Acquir Immune Defic Syndr 53: 86-94. [Crossref]

86. Caldwell MB, Oxtoby MJ, Simonds RJ, Lou Lindegren M, Rogers MF (1994) 1994 revised classification system for human immunodeficiency virus infection in children less than 13 years of age. Morbidity and Mortality Weekly Report: Recommendations and Reports. 1994 Sep 30: iii-10.

87. World Health Organization (2007) WHO case definitions of HIV for surveillance and revised clinical staging and immunological classification of HIV-related disease in adults and children. Switzerland

88. Barbarini G, Barbaro G (2003) Incidence of the involvement of the cardiovascular system in HIV infection. Aids 17: S46-S50. [Crossref]

89. Jain N, Reddy DH, Verma SP, Khanna R, Vaish AK, et al. (2014) Cardiac abnormalities in HIV-positive patients: results from an observational study in India. $J$ Int Assoc Provid AIDS Care 13: 40-46. [Crossref]

90. Friis-Møller N, Sabin CA, Weber R, d'Arminio MA, El-Sadr WM, Reiss P, Thiébaut R, Morfeldt L, De Wit S, Pradier C, Calvo G. (2003) Combination antiretroviral therapy and the risk of myocardial infarction. $N$ Engl J Med 349: 1993-2003. [Crossref]

91. D'Arminio A, Sabin CA, Phillips AN, Reiss P, Weber R, Kirk O, El-Sadr W, De Wit S, Mateu S, Petoumenos K, Dabis F. Cardio-and cerebrovascular events in HIV-infected persons. AIDSAids 18: 1811-1817. [Crossref]

92. Lewis W, Haase CP, Raidel SM, Russ RB, Sutliff RL, et al. (2001) Combined antiretroviral therapy causes cardiomyopathy and elevates plasma lactate in transgenic AIDS mice. Laboratory Investigation 81: 1527-1536. [Crossref]

93. Chaisson RE, Allain JP, Leuther M, Volberding PA (1986) Significant changes in HIV antigen level in the serum of patients treated with azidothymidine. $N$ Engl J Med 315: 1610-1611. [Crossref]

94. Skowron G, Chowdhry S, Stevens MR (2006) Stavudine, didanosine, and zalcitabine. In Reverse Transcriptase Inhibitors in HIV/AIDS Therapy, 77-132. Humana Press.

95. Yarchoan R, Weinhold K, Lyerly HK, Gelmann E, Blum R, et al. (1986) Administration of 3'-azido-3'-deoxythymidine, an inhibitor of HTLV-III/LAV replication, to patients with AIDS or AIDS-related complex. Lancet 327: 575-580. [Crossref]

96. Stanley SK (1998) Guidelines for the use of antiretroviral agents in HIV-infected adults and adolescents. Morbidity and Mortality Weekly Report: Recommendations and Reports 24: 39-82. [Crossref]
97. Arnaudo E, Shanske S, DiMauro S, Schon EA, Moraes CT, et al. (1995) Depletion of muscle mitochondrial DNA in AIDS patients with zidovudine-induced myopathy. Lancet 337: 508-510. [Crossref]

98. Dalakas MC, Illa I, Pezeshkpour GH, Laukaitis JP, Cohen B, et al. (1990) Mitochondrial myopathy caused by long-term zidovudine therapy. N Engl J Med 322: 1098-1105. [Crossref]

99. Shoubridge EA (1994) Mitochondrial DNA diseases: histological and cellular studies J Bioenerg Biomembr 26: 301-310. [Crossref]

100. Chariot P, Monnet I, Mouchet M, Rohr M, Lefaucheur JP, et al. (1994) Determination of the blood lactate: pyruvate ratio as a noninvasive test for the diagnosis of zidovudine myopathy. Arthritis \& Rheumatism 37: 583-586. [Crossref]

101. Corcuera MP, Lopez AB, Martinez-Rodriguez R, Picazo AT, Gomez FA, et al. (1994) Histochemical and ultrastructural changes induced by zidovudine in mitochondria of rat cardiac muscle. Eur J Histochem 38: 311-318. [Crossref]

102. Lamperth L, Dalakas MC, Dagani F, Anderson J, Ferrari R (1991) Abnormal skeletal and cardiac muscle mitochondria induced by zidovudine (AZT) in human muscle in vitro and in an animal model Lab Invest 65: 742-751. [Crossref]

103. Lewis W, Papoian T, Gonzalez B, Louie H, Kelly DP, et al. (1991) Mitochondria ultrastructural and molecular changes induced by zidovudine in rat hearts. Lab Invest 65: 228-236. [Crossref]

104. Lewis W, Gonzalez B, Chomyn A, Papoian T (1992) Zidovudine induces molecular, biochemical, and ultrastructural changes in rat skeletal muscle mitochondria. J Clin Invest 89: 1354-1360. [Crossref]

105. Lewis W (2000) Cardiomyopathy in AIDS: a pathophysiological perspective. Prog Cardiovasc Dis 43: 151-170. [Crossref]

106. Barbaro G, Di Lorenzo G, Grisorio B, Barbarini G (1998) Incidence of dilated cardiomyopathy and detection of HIV in myocardial cells of HIV-positive patients. $N$ Eng J Med 339: 1093-1099. [Crossref]

107. Barbaro G, Di Lorenzo G, Soldini M, Giancaspro G, Grisorio B, et al. (2000) Clinica course of cardiomyopathy in HIV-infected patients with or without encephalopathy related to the myocardial expression of tumour necrosis factor- $\alpha$ and nitric oxide synthase. Aids 14: 827-838. [Crossref]

108. Herskowitz A, Willoughby SB, Baughman KL, Schulman SP, Bartlett JD (1992) Cardiomyopathy associated with antiretroviral therapy in patients with HIV infection: a report of six cases. Ann Intern Med 116: 311-313. [Crossref]

109. Patel K, Van Dyke RB, Mittleman MA, Colan SD, Oleske JM, et al. (2012) The impact of HAART on cardiomyopathy among children and adolescents perinatally infected with HIV-1. Aids 26: 2027-2037. [Crossref]

110. Domanski MJ, Sloas MM, Follmann DA, Scalise III PP, Tucker EE, et al. (1995) Effect of zidovudine and didanosine treatment on heart function in children infected with human immunodeficiency virus. J Pediatr 127: 137-146. [Crossref]

111. Sabin CA, Worm SW, Weber R, Reiss P, El-Sadr W, et al. (2008) Use of nucleoside reverse transcriptase inhibitors and risk of myocardial infarction in HIV-infected patients enrolled in the D: A: D study: a multi-cohort collaboration. Lancet 371: 1417-1426. [Crossref]

112. Whittington R, Brogden RN (1992) Zalcitabine. Drugs 44: 656-683. [Crossref]

113. Adkins JC, Peters DH, Faulds D. Zalcitabine (1997) An update of its pharmacodynamic and pharmacokinetic properties and clinical efficacy in the management of HIV infection. Drugs 53: 1054-1080. [Crossref]

114. Bakshi SS, Britto P, Capparelli E, Mofenson L, Fowler MG, et al. (1997) Evaluation of pharmacokinetics, safety, tolerance, and activity of combination of zalcitabine and zidovudine in stable, zidovudine-treated pediatric patients with human immunodeficiency virus infection. J Infect Dis 175: 1039-1050. [Crossref]

115. Lewis W (2003) Mitochondrial DNA replication, nucleoside reverse-transcriptase inhibitors, and AIDS cardiomyopathy. Prog Cardiovasc Dis 45: 305-318. [Crossref]

116. Birkus G, Hitchcock MJ, Cihlar T (2002) Assessment of mitochondrial toxicity in human cells treated with tenofovir: comparison with other nucleoside reverse transcriptase inhibitors. Antimicrob Agents Chemother 46: 716-723. [Crossref]

117. Brinkman K, ter Hofstede HJ, Burger DM, Smeitink JA, Koopmans PP (1998) Adverse effects of reverse transcriptase inhibitors: mitochondrial toxicity as common pathway. Aids 12: 1735-1744. [Crossref]

118. Benbrik E, Chariot P, Bonavaud S, Ammi-Saïd M, Frisdal E, et al. (1997) Cellular and mitochondrial toxicity of zidovudine (AZT), didanosine (ddI) and zalcitabine (ddC) on cultured human muscle cells. J Neurol Sci 149: 19-25. [Crossref] 
119. Medina DJ, Tsai CH, Hsiung GD, Cheng YC (1994) Comparison of mitochondrial morphology, mitochondrial DNA content, and cell viability in cultured cells treated with three anti-human immunodeficiency virus dideoxynucleosides. Antimicrob Agents Chemother 38: 1824-1828. [Crossref]

120. Saitoh A, Fenton T, Alvero C, Fletcher CV, Spector SA (2007) Impact of nucleoside reverse transcriptase inhibitors on mitochondria in human immunodeficiency virus type 1-infected children receiving highly active antiretroviral therapy. Antimicrob Agents Chemother 51: 4236-4242. [Crossref]

121. Mondy KE, Gottdiener J, Overton ET, Henry K, Bush T, et al. (2011) High prevalence of echocardiographic abnormalities among HIV-infected persons in the era of highly active antiretroviral therapy. Clin Infect Dis 52: 378-386. [Crossref]

122. Chiappini F, Teicher E, Saffroy R, Pham P, Falissard B, et al. (2004) Prospective evaluation of blood concentration of mitochondrial DNA as a marker of toxicity in 157 consecutively recruited untreated or HAART-treated HIV-positive patients. Lab Invest 84: 908-914. [Crossref]

123. Cote HC, Brumme ZL, Craib KJ, Alexander CS, Wynhoven B, et al. (2002) Changes in mitochondrial DNA as a marker of nucleoside toxicity in HIV-infected patients. $N$ Eng J Med 346: 811-820. [Crossref]

124. Cote HC, Yip B, Asselin JJ, Chan JW, Hogg RS, et al. (2003) Mitochondrial: nuclear DNA ratios in peripheral blood cells from human immunodeficiency virus (HIV)infected patients who received selected HIV antiretroviral drug regimens. $J$ Infect Dis 187: 1972-1976. [Crossref]

125. Mccomsey G, Bai RK, Maa JF, Seekins D, Wong LJ (2005) Extensive investigations of mitochondrial DNA genome in treated HIV-infected subjects: beyond mitochondrial DNA depletion. J Acquir Immune Defic Syndr 39: 181-188. [Crossref]

126. McComsey GA, Paulsen DM, Lonergan JT, Hessenthaler SM, Hoppel CL, et al. (2005) Improvements in lipoatrophy, mitochondrial DNA levels and fat apoptosis after replacing stavudine with abacavir or zidovudine. Aids 19: 15-23. [Crossref]

127. Cherry CL, Gahan ME, McArthur JC, Lewin SR, Hoy JF, et al. (1999) Exposure to dideoxynucleosides is reflected in lowered mitochondrial DNA in subcutaneous fat. $J$ Acquir Immune Defic Syndr 30: 271-277. [Crossref]

128. Hoy JF, Gahan ME, Carr A, Smith D, Lewin SR, et al. (2004) Changes in mitochondrial DNA in peripheral blood mononuclear cells from HIV-infected patients with lipoatrophy randomized to receive abacavir J Infect Dis 190: 688-692. [Crossref]

129. McComsey G, Tan DJ, Lederman M, Wilson E, Wong LJ (2002) Analysis of the mitochondrial DNA genome in the peripheral blood leukocytes of HIV-infected patients with or without lipoatrophy. Aids 16: 513-518. [Crossref]

130. Petit C, Mathez D, Barthélémy C, Leste-Lasserre T, Naviaux RK, et al. (2003) Quantitation of blood lymphocyte mitochondrial DNA for the monitoring of antiretroviral drug-induced mitochondrial DNA depletion. J Acquir Immune Defic Syndr 33: 461-469. [Crossref]

131. Reiss P, Casula M, De Ronde A, Weverling GJ, Goudsmit J, et al. (2004) Greater and more rapid depletion of mitochondrial DNA in blood of patients treated with dual (zidovudine+ didanosine or zidovudine+ zalcitabine) vs. single (zidovudine) nucleoside reverse transcriptase inhibitors. HIV Medicine 5: 11-14. [Crossref]

132. Van Der Valk M, Casula M, Weverlingz GJ, Van Kuijk K, van Eck-Smit B, et al (2004) Prevalence of lipoatrophy and mitochondrial DNA content of blood and subcutaneous fat in HIV-1-infected patients randomly allocated to zidovudine-or stavudine-based therapy. Antivir Ther 9: 385-394. [Crossref]

133. Setzer B, Schlesier M, Walker UA (2005) Effects of didanosine-related depletion of mtDNA in human T lymphocytes. J Infect Dis 191: 848-855. [Crossref]

134. Brinkman K (2005) Lipoatrophy and mitochondrial DNA assays: see all, know all? Aids. 19: 91-92. [Crossref]

135. Yogasundaram H, Hung W, Paterson ID, Sergi C, Oudit GY (2018) Chloroquineinduced cardiomyopathy: a reversible cause of heart failure. ESC Heart Fail 5: 372 375. [Crossref]

136. August C, Holzhausen HJ, Schmoldt A, Pompecki R, Schroder S (1995) Histological and ultrastructural findings in chloroquine-induced cardiomyopathy. J Mol Med 73: 73-77. [Crossref]

137. Page RL, O'bryant CL, Cheng D, Dow TJ, Ky B, et al. (2016) Drugs that may cause or exacerbate heart failure: a scientific statement from the American Heart Association. Circulation 134: e32-69. [Crossref]

138. Yogasundaram H, Putko BN, Tien J, Paterson DI, Cujec B, et al. (2014) Hydroxychloroquine-induced cardiomyopathy: case report, pathophysiology, diagnosis, and treatment. Can J Cardio 30: 1706-1715. [Crossref]
139. Volkov VP (2018) Antipsychotic cardiomyopathy: to the problem of clinical diagnosis. MOJ Toxicol 4: 238-240.

140. Ohlow MJ, Moosmann B (2011) Phenothiazine: the seven lives of pharmacology's first lead structure. Drug Discov Today 16: 119-131. [Crossref]

141. Jaszczyszyn A, Gąsiorowski K, Świątek P, Malinka W, Cieślik-Boczula K, et al (2012) Chemical structure of phenothiazines and their biological activity. Pharmacol Rep 64: 16-23. [Crossref]

142. Sudeshna G, Parimal K (2010) Multiple non-psychiatric effects of phenothiazines: a review. Eur J Pharmacol 648: 6-14. [Crossref]

143. Wu CH, Bai LY, Tsai MH, Chu PC, Chiu CF, et al. (2016) Pharmacological exploitation of the phenothiazine antipsychotics to develop novel antitumor agents: A drug repurposing strategy. Sci Rep 6: 27540. [Crossref]

144. About secondary phenothiazine-induced cardiomyopathy (2011) Klin Med (Mosk) 89: 30-33. [Crossref]

145. Volkov VP (2009) Phenothiazine-induced dilatation cardiomyopathy: selected aspects of clinical course and morphology. Klin Med (Mosk) 87: 13-16. [Crossref]

146. Bryan J (2014) After 30 years, clozapine is still best for treatment-resistant patients Pharmaceutical Journal 11: 15.

147. Rostagno C, Domenichetti S, Pastorelli F, Gensini GF (2011) Clozapine associated cardiomyopathy: a cluster of 3 cases. Intern Emerg Med 6: 281-283. [Crossref]

148. Ronaldson KJ, Taylor AJ, Fitzgerald PB, Topliss DJ, Elsik M, McNeil JJ (2010) Diagnostic characteristics of clozapine-induced myocarditis identified by an analysis of 38 cases and 47 controls. J Clin Psychiatry 71: 976-981. [Crossref]

149. Makhoul B, Hochberg I, Rispler S, Azzam ZS (2008) Dilated cardiomyopathy: an unusual complication of clozapine therapy. Nat Clin Pract Cardiovasc Med 5: 566570. [Crossref]

150. Volkov VP (2009) Features of an electrocardiogram at a phenothiazine cardiomyopathy. Upper Volga Med J 7: 3-7.

151. Volkov VP (2013) Dynamics of arterial pressure at an antipsychotic cardiomyopathy In Innovations in science: materials of the XIXth international correspondence scientific and practical conference. Novosibirsk: SibAC pp. 130-137.

152. Volkov VP (2012) Morphological features of an antipsychotic cardiomyopathy In Medicine: calls of today: international correspondence scientific conference, Chelyabinsk Jun pp. 33-36.

153. Volkov VP (2012) Morphometric aspects of a morphogenesis of an antipsychotic cardiomyopathy. Ros J Cardiol 3: 68-73.

154. Volkov VP (2013) Clinical characteristic of an antipsychotic cardiomyopathy. In Volkov VP (Ed.) Actual problems of therapeutic clinic: collective scientific monograph. Novosibirsk: SibAC 94-116.

155. Volkov VP (2009) Sudden death of patients with schizophrenia. Upper Volga Med J 7: 3-7.

156. Volkov VP (2013) Sudden cardiac death at schizophrenia. Mental health 1:50-54.

157. Volkov VP (2012) Electrocardiographic manifestations of an antipsychotic cardiomyopathy at patients with schizophrenia at stages of its morphogenesis. Upper Volga Med J 10: 13-16.

158. Volkov VP (2013) Antipsychotic cardiomyopathy: diagnostic approaches and criteria of the diagnosis. Doctor 9: 69-71.

159. Volkov VP (2012). Antipsychotic cardiomyopathy. In: Volkov VP, Zacharov RI, (Eds.) Pharmacotherapy: new prospects and problems: collective scientific monograph. Novosibirsk: Siberian Association of Consultants 65-84.

160. Volkov VP (2013) Antipsychotic cardiomyopathy: clinical-morphological criteria of the diagnosis. Curing Doctor 10: 77-80.

161. Bray A, Reid R (2011) Successful clozapine rechallenge after acute myocarditis. Aust N Z J Psychiatry 45: 90. [Crossref]

162. Granja-Ingram NM, James J, Clark N, Stovall J, Heckers S (2013) Successful reexposure to clozapine after eosinophilia and clinically suspected myocarditis. Braz J Psychiatry 35: 95-96. [Crossref]

163. Raj MJ, Benson R (1975) Phenothiazines and the electrocardiogram. Postgrad Med J 51: 65-68. [Crossref]

164. Kilian JG, Kerr K, Lawrence C, Celermajer DS (1999) Myocarditis and cardiomyopathy associated with clozapine. Lancet 354: 1841-1845. [Crossref] 
165. Majonga ED, Rehman AM, Simms V, Mchugh G, Mujuru HA, et al. (2018) High prevalence of echocardiographic abnormalities in older HIV-infected children taking antiretroviral therapy. Aids 32: 2739-2748. [Crossref]

166. Gottdiener JS, Appelbaum FR, Ferrans VJ, Deisseroth A, Ziegler J (1981) Cardiotoxicity associated with high-dose cyclophosphamide therapy. Arch Intern Med 141: 758-763. [Crossref]

167. Steinherz LJ, Steinherz PG, Mangiacasale D, O'Reilly R, Allen J, et al. (1981) Cardiac changes with cyclophosphamide. Med Pediatr Oncol 9: 417-422. [Crossref]

168. Godoy LY, Fukushige J, Igarashi H, Matsuzaki A, Ueda K (1997) Anthracyclineinduced cardiotoxicity in children with malignancies. Acta Paediatr Jpn 39: 188-193. [Crossref]

169. Dazzi H, Kaufmann K, Follath F (2001) Anthracycline-induced acute cardiotoxicity in adults treated for leukaemia: Analysis of the clinico-pathological aspects of documented acute anthracycline-induced cardiotoxicity in patients treated for acute leukaemia at the University Hospital of Zürich, Switzerland, between 1990 and 1996. Ann Oncol 12: 963-966. [Crossref]

170. Zver S, Zadnik V, Bunc M, Rogel P, Cernelc P, et al. (2007) Cardiac toxicity of highdose cyclophosphamide in patients with multiple myeloma undergoing autologous hematopoietic stem cell transplantation. Int J Hematol 85: 408-414. [Crossref]

171. Shaikh AS, Saleem AF, Mohsin SS, Alam MM, Ahmed MA (2013) Anthracyclineinduced cardiotoxicity: prospective cohort study from Pakistan. BMJ 3: e003663. [Crossref]

172. Mercuro G, Cadeddu C, Piras A, Dessi M, Madeddu C, et al. (2007) Early epirubicininduced myocardial dysfunction revealed by serial tissue Doppler echocardiography: correlation with inflammatory and oxidative stress markers. Oncologist 12: 11241133. [Crossref]

173. Jurcut R, Wildiers H, Ganame J, D'hooge J, De Backer J, et al. (2008) Strain rate imaging detects early cardiac effects of pegylated liposomal Doxorubicin as adjuvant therapy in elderly patients with breast cancer. J Am Soc Echocardiogr 21: 1283-1289. [Crossref]

174. Mantovani G, Madeddu C, Cadeddu C, Dessi M, Piras A, et al. (2008) Persistence, up to 18 months of follow-up, of epirubicin-induced myocardial dysfunction detected early by serial tissue Doppler echocardiography: correlation with inflammatory and oxidative stress markers. Oncologist 13: 1296-1305. [Crossref]

175. Wildiers H, Jurcut R, Ganame J, Herbots L, Neven P, et al. (2008) A pilot study to investigate the feasibility and cardiac effects of pegylated liposomal doxorubicin (PL-DOX) as adjuvant therapy in medically fit elderly breast cancer patients. Crit Rev Oncol Hematol 67: 133-138. [Crossref]

176. Fallah-Rad N, Walker JR, Wassef A, Lytwyn M, Bohonis S, et al. (2011) The utility of cardiac biomarkers, tissue velocity and strain imaging, and cardiac magnetic resonance imaging in predicting early left ventricular dysfunction in patients with human epidermal growth factor receptor II-positive breast cancer treated with adjuvant trastuzumab therapy. J Am Coll Cardiol 57: 2263-2270. [Crossref]

177. Sawaya H, Sebag IA, Plana JC, Januzzi JL, Ky B, et al. (2011) Early detection and prediction of cardiotoxicity in chemotherapy-treated patients. Am J Cardiol 107: 1375-1380. [Crossref]

178. Stoodley PW, Richards DA, Hui R, Boyd A, Harnett PR, et al. (2011) Twodimensional myocardial strain imaging detects changes in left ventricular systolic function immediately after anthracycline chemotherapy. Eur J Echocardiogr 12: 945952. [Crossref]

179. Al-Biltagi M, Abd Rab Elrasoul Tolba O, El-Shanshory MR, Abd El-Aziz El-Shitany N, El-Sayed El-Hawary E (2012) Strain echocardiography in early detection of doxorubicin-induced left ventricular dysfunction in children with acute lymphoblastic leukemia. ISRN Pediatr 2: 1-10. [Crossref]

180. Poterucha JT, Kutty S, Lindquist RK, Li L, Eidem BW (2012) Changes in left ventricular longitudinal strain with anthracycline chemotherapy in adolescents precede subsequent decreased left ventricular ejection fraction. $J \mathrm{Am} S \mathrm{Soc}$ Echocardiogr 25: 733-740. [Crossref]

181. Sawaya H, Sebag IA, Plana JC, Januzzi JL, Ky B, et al. (2012) Assessment of echocardiography and biomarkers for the extended prediction of cardiotoxicity in patients treated with anthracyclines, taxanes, and trastuzumab. Circ Cardiovasc Imaging 5: 596-603. [Crossref]

182. Stoodley PW, Richards DA, Boyd A, Hui R, Harnett PR, et al (2012) Altered left ventricular longitudinal diastolic function correlates with reduced systolic function immediately after anthracycline chemotherapy. Eur Heart J Cardiovasc Imaging 14: 228-234. [Crossref]
183. Zhang H, Shen WS, Gao CH, Deng LC, Shen D (2012) Protective effects of salidroside on epirubicin-induced early left ventricular regional systolic dysfunction in patients with breast cancer. Drugs RD 12: 101-106. [Crossref]

184. Baratta S, Damiano MA, Marchese ML, Trucco JI, Rizzo MM, et al. (2013) Serum markers, conventional Doppler echocardiography and two-dimensional systolic strain in the diagnosis of chemotherapy-induced myocardial toxicity. Argentine Journal of Cardiology 81: 133-138.

185. Negishi K, Negishi T, Hare JL, Haluska BA, Plana JC, et al. (2013) Independent and incremental value of deformation indices for prediction of trastuzumab-induced cardiotoxicity. J Am Soc Echocardiogr 26: 493-498. [Crossref]

186. Stoodley PW, Richards DA, Boyd A, Hui R, Harnett PR, et al. (2013) Lef ventricular systolic function in HER2/neu negative breast cancer patients treated with anthracycline chemotherapy: a comparative analysis of left ventricular ejection fraction and myocardial strain imaging over 12 months. Eur J Cancer 49: 3396-3403. [Crossref]

187. Emren SV, Tuluce SY, Levent F, Tuluce K, Kalkan T, et al. (2015) Evaluation of Trastuzumab-induced early cardiac dysfunction using two-dimensional Strain Echocardiography. Med Ultrason 17: 496-502. [Crossref]

188. Gripp ED, Oliveira GE, Feijó LA, Garcia MI, Xavier SS, et al. (2018) Global longitudinal strain accuracy for cardiotoxicity prediction in a cohort of breast cancer patients during anthracycline and/or trastuzumab treatment. Arq. Bras. Cardiol 110: 140-150. [Crossref]

189. Milei J, Marantz A, Ale J, Vazquez A, Buceta JE (1987) Prevention of adriamycininduced cardiotoxicity by prenylamine: a pilot double blind study. Cancer Drug Deliv 4: 129-136. [Crossref]

190. Speyer JL, Green MD, Zeleniuch-Jacquotte A, Wernz JC, Rey M, et al. (1992) ICRF187 permits longer treatment with doxorubicin in women with breast cancer. $J$ Clin Oncol 10: 117-127. [Crossref]

191. Venturini M, Michelotti A, Del Mastro L, Gallo L, Carnino F, et al. (1996) Multicenter randomized controlled clinical trial to evaluate cardioprotection of dexrazoxane versus no cardioprotection in women receiving epirubicin chemotherapy for advanced breast cancer. J Clin Oncol 14: 3112-3120. [Crossref]

192. Silber JH, Cnaan A, Clark BJ, Paridon SM, Chin AJ, et al. (2004) Enalapril to prevent cardiac function decline in long-term survivors of pediatric cancer exposed to anthracyclines. J Clin Oncol 22: 820-828. [Crossref]

193. Cardinale D, Colombo A, Sandri MT, Lamantia G, Colombo N, et al. (2006) Prevention of high-dose chemotherapy-induced cardiotoxicity in high-risk patients by angiotensin-converting enzyme inhibition. Circulation 114: 2474-2481. [Crossref]

194. Kalay N, Basar E, Ozdogru I, Er O, Cetinkaya Y, et al. (2006) Protective effects of carvedilol against anthracycline-induced cardiomyopathy. J Am Coll Cardiol 48: 2258-2262. [Crossref]

195. Marty M, Espie M, Llombart A, Monnier A, Rapoport BL, et al. (2006) Multicenter randomized phase III study of the cardioprotective effect of dexrazoxane (Cardioxane $\mathbb{R})$ in advanced/metastatic breast cancer patients treated with anthracycline-based chemotherapy. Ann Oncol 17: 614-622. [Crossref]

196. Georgakopoulos P, Roussou P, Matsakas E, Karavidas A, Anagnostopoulos N, et al (2010) Cardioprotective effect of metoprolol and enalapril in doxorubicin-treated lymphoma patients: a prospective, parallel-group, randomized, controlled study with 36-month follow-up. Am J Hematol 85: 894-896. [Crossref]

197. Acar Z, Kale A, Turgut M, Demircan S, Durna K, et al. (2011) Efficiency of atorvastatin in the protection of anthracycline-induced cardiomyopathy. $J$ Am Coll Cardiol 58: 988-989. [Crossref]

198. Seicean S, Seicean A, Plana JC, Budd GT, Marwick TH (2012) Effect of statin therapy on the risk for incident heart failure in patients with breast cancer receiving anthracycline chemotherapy: an observational clinical cohort study. J Am Coll Cardiol 60: 2384-2390. [Crossref]

199. Bosch X, Rovira M, Sitges M, Domènech A, Ortiz-Pérez JT, et al. (2013) Enalapril and carvedilol for preventing chemotherapy-induced left ventricular systolic dysfunction in patients with malignant hemopathies: the OVERCOME trial (preventiOn of left Ventricular dysfunction with Enalapril and caRvedilol in patients submitted to intensive ChemOtherapy for the treatment of Malignant hEmopathies) $\mathrm{J}$ Am Coll Cardiol 61: 2355-2362. [Crossref]

200. Seicean S, Seicean A, Alan N, Plana JC, Budd GT, et al. (2013) Cardioprotective effect of Beta-Adrenoceptor blockade in breast cancer patients undergoing chemotherapy: a follow-up study of heart failure. Circ Heart Fail 6: 420-426. [Crossref]

201. Bleyer WA (1990) The impact of childhood cancer on the United States and the world. CA Cancer J Clin 40: 355-367. [Crossref] 
202. Friedman DL, Meadows AT (2002). Late effects of childhood cancer therapy. In Vichinsky E, Walters M, Feusner J (eds): Pediatric Clinics of North American Hematology and Oncology. Philadelphia, PA, WB Saunders pp: 1083-1106.

203. Morandi P, Ruffini PA, Benvenuto GM, La Vecchia L, Mezzena G, et al. (2001) Serum cardiac troponin I levels and ECG/Echo monitoring in breast cancer patients undergoing high-dose $(7 \mathrm{~g} / \mathrm{m}$ 2) cyclophosphamide. Bone Marrow Transplant 28: 277-282. [Crossref]

204. Yusuf SW, Ilias-Khan NA, Durand JB (2011) Chemotherapy-induced cardiomyopathy. Expert Rev Cardiovasc Ther 9: 231-243. [Crossref]

205. Plana JC, Galderisi M, Barac A, Ewer MS, Ky B, et al. (2014) Expert consensus for multimodality imaging evaluation of adult patients during and after cancer therapy: a report from the American Society of Echocardiography and the European Association of Cardiovascular Imaging. J Am Soc Echocardiogr 15: 1063-1093. [Crossref]

206. Tjeerdsma G, Meinardi MT, van Der Graaf WT, van Den Berg MP, et al. (1999) Early detection of anthracycline induced cardiotoxicity in asymptomatic patients with normal left ventricular systolic function: autonomic versus echocardiographic variables. Heart 81: 419-423. [Crossref]

207. Ewer MS, Ali MK, Mackay B, Wallace S, Valdivieso M, et al. (1984) A comparison of cardiac biopsy grades and ejection fraction estimations in patients receiving Adriamycin. J Clin Oncol 2: 112-117. [Crossref]

208. Tadic M, Cuspidi C (2017) The role of echocardiography in detection of chemotherapy-induced cardiotoxicity in breast cancer patients. Int J Cancer Manag 10: e8109.

209. Jassal DS, Han SY, Hans C, Sharma A, Fang T, et al. (2009) Utility of tissue Doppler and strain rate imaging in the early detection of trastuzumab and anthracycline mediated cardiomyopathy. J Am Soc Echocardiogr 22: 418-424. [Crossref]

210. Hoit BD (2009) Detection of myocardial dysfunction during cancer chemotherapy with tissue Doppler imaging: a canary in the coal mine? J Am Soc Echocardiogr 22: 425-426. [Crossref]

211. Guerra F, Marchesini M, Contadini D, Menditto A, Morelli M, et al. (2016) Speckletracking global longitudinal strain as an early predictor of cardiotoxicity in breast carcinoma. Support Care Cancer 24: 3139-3145. [Crossref]

212. Fei HW, Ali MT, Tan TC, Cheng KH, Salama L, et al. (2016) Left Ventricular Global Longitudinal Strain in HER-2+ Breast Cancer Patients Treated with Anthracyclines and Trastuzumab Who Develop Cardiotoxicity Is Associated with Subsequent Recovery of Left Ventricular Ejection Fraction. Echocardiography 33: 519-526. [Crossref]
213. Tan TC, Bouras S, Sawaya H, Sebag IA, Cohen V, et al. (2015) Time Trends of Left Ventricular Ejection Fraction and Myocardial Deformation Indices in a Cohort of Women with Breast Cancer Treated with Anthracyclines, Taxanes, and Trastuzumab. $J$ Am Soc Echocardiogr 28: 509-514. [Crossref]

214. Khouri MG, Hornsby WE, Risum N, Velazquez EJ, Thomas S, et al. (2014) Utility of 3-dimensional echocardiography, global longitudinal strain, and exercise stress echocardiography to detect cardiac dysfunction in breast cancer patients treated with doxorubicin containing adjuvant therapy. Breast Cancer Res Treat 143: 531-539. [Crossref]

215. Motoki H, Koyama J, Nakazawa H, Aizawa K, Kasai H, et al. (2012) Torsion analysis in the early detection of anthracycline-mediated cardiomyopathy. Eur Heart $J$ Cardiovasc Imaging 13: 95-103. [Crossref]

216. Van Dalen EC, Caron HN, Dickinson HO (2011) Cardioprotective interventions for cancer patients receiving anthracyclines. Cochrane Database of Syst Rev 15: CD003917. [Crossref]

217. Lipshultz SE, Rifai N, Dalton VM, Levy DE, Silverman LB, et al. (2004) The effect of dexrazoxane on myocardial injury in doxorubicin-treated children with acute lymphoblastic leukaemia. $N$ Eng J Med 351: 145-153. [Crossref]

218. Lipshultz SE, Scully RE, Lipsitz SR, Sallan SE, Silverman LB, et al. (2010) Assessment of dexrazoxane as a cardioprotectant in doxorubicin-treated children with high-risk acute lymphoblastic leukaemia: long-term follow-up of a prospective, randomised, multicentre trial. Lancet Oncol 11: 950-961. [Crossref]

219. Tebbi CK, London WB, Friedman D, Villaluna D, De Alarcon PA, et al. (2007) Dexrazoxane-associated risk for acute myeloid leukemia/myelodysplastic syndrome and other secondary malignancies in pediatric Hodgkin's disease. J Clin Oncol 25: 493-500. [Crossref]

220. Borghi C, Bacchelli S, Degli Esposti D, Ambrosioni E (2004) A review of the angiotensin-converting enzyme inhibitor, zofenopril, in the treatment of cardiovascular diseases. Expert Opin Pharmacother 5: 1965-1977. [Crossref]

221. Lyu YL, Kerrigan JE, Lin CP, Azarova AM, Tsai YC, et al. (2007) Topoisomerase IIß mediated DNA double-strand breaks: implicationsin doxorubicin cardiotoxicity and prevention by dexrazoxane. Cancer Res 67: 8839-8846. [Crossref]

222. Hiona A, Lee AS, Nagendran J, Xie X, Connolly AJ, et al. (2011) Pretreatment with angiotensin-converting enzyme inhibitor improves doxorubicin-induced cardiomyopathy via preservation of mitochondrial function. $J$ Thorac Cardiovasc Surg 142: 396-403. [Crossref]

Copyright: (C2019 Albakri A. This is an open-access article distributed under the terms of the Creative Commons Attribution License, which permits unrestricted use, distribution, and reproduction in any medium, provided the original author and source are credited. 